Appears in:

Kobbacy, K.A., Vadera, S. and Rasmi, M. (2007), Al and OR in management of operations: history and trends, Journal of the Operational Research Society, Vol 58, pp10-28.

doi:10.1057/palgrave.jors.2602132

\title{
AI and OR in Management of Operations: History and Trends
}

\author{
Khairy A. H. Kobbacy*, Sunil Vadera+ and Mohamed H. Rasmy** \\ *School of Accounting, Econonics and Management Sciences, \\ +School of Computing, Science and Engineering \\ University of Salford, Salford M5 4WT, UK \\ ** Faculty of Computers and Information, \\ Cairo University, Gizza, Egypt.
}

\begin{abstract}
The last decade has seen a considerable growth in the use of AI for operations management with the aim of finding solutions to problems that are increasing in complexity and scale.

This paper begins by setting the context for the survey through a historical perspective of OR and AI. An extensive survey of applications of AI techniques for operations management, covering a total of over 1200 papers published from 1995 to 2004 is then presented.

The papers are categorised into four areas of operations management: (a) design, (b) scheduling, (c) process planning and control and (d) quality, maintenance and fault diagnosis. Each of the four areas is categorised in terms of the AI techniques used: genetic algorithms, case based reasoning, knowledge based systems, fuzzy logic and hybrid techniques.
\end{abstract}

The trends over the last decade are identified, discussed with respect to expected trends and directions for future work suggested.

Keywords: Operations Management, Artificial Intelligence

\section{INTRODUCTION}

The 1980s saw a significant growth in research in Operations Management including scheduling, project planning, fault diagnosis and maintenance, aimed at improving the efficiency and effectiveness of operations management. These research areas remain 
the subject of many conferences, journals and research programmes. So at first sight, it appears that the problems remain unsolved despite the significant investment in attempts at finding solutions by academia, industry and governments. There are several reasons for this apparent lack of progress: (a) many of the solutions formulated in the 1980's were for well defined situations; (b) the solutions assumed that accurate data was available for the models; and (c) the solutions were too computationally expensive to be practical.

In addition to these, the world has changed dramatically since the 1980s, with businesses operating in a global market, in an environment that results in problems that are more complex and on a larger scale than ever before. On reflection, therefore, it should not be surprising that, on their own, our old solutions are inadequate for today's problems in operations management.

One approach to the kind of problems we face in operations management today, was proposed by Simon (1987), who, in his keynote paper "Two heads are better than one" proposed the use of a combination of Operational Research (OR) and Artificial Intelligence (AI). This combination seemed natural to Simon, who appreciated the complementary strengths of the two disciplines, with OR strong on well founded mathematical models and AI strong on heuristics.

This potential has been recognised by both communities, with an increasing number of publications at the OR-AI interface. In recent years, there have also been conferences, such as the European Conference on Intelligent Management Systems in Operations that has been organised by two of the authors (KAHK \& SV) since 1997 with the aim of bringing together researchers from both communities. These conference have provided the motivation for the authors to survey the field and identify the progress being made, trends and areas of future work (Meziane et al. 2000; Proudlove et al. 1998). The 2005 conference provided an appropriate time to carry out the most comprehensive survey to date that is based on much more data and over a longer time period than any of the authors' previous surveys. The survey aims to address the following questions:

(a) What is the current direction of research on applying AI techniques in Operations Management?

(b) What are the trends in terms of utilising particular AI techniques for subproblems in Operations Management?

(c) What should the future direction of research be?

To answer these questions, the authors survey papers published from 1995 to 2004, and indexed in Elsevier's Science Direct (http://www.sciencedirect.com/, accessed February 2005) which covers over 1800 journals in Science, Technology and Medicine.

The paper begins by setting the context for the survey in section 2, where a historical perspective of Operations Research and Artificial Intelligence is presented. Section 3 presents an overview of the type and range of research on applying AI in Operations Management by citing representative and innovative work. Section 4 discusses the results obtained, identifying areas of major application, historical trends and areas that need future research. 


\section{CHARACTERISTICS OF OR AND AI}

OR flourished during the second world war in military applications and thereafter as a result of the development of the electronic computers. The term OR was first used about 1936, though decision models can be traced back to the beginning of the 20th century. During the period from the fifties to the seventies, it expanded into Industry and Government, aided in the UK by nationalisation policies and in the US as a result of OR scientists moving to industry despite the large defence contracts (Ackoff and Sasieni 1968).

Many definitions of OR have been offered and, equally, many arguments that suggest why it cannot be defined (e.g, by Ackoff and Sasieni (1968)). However, a widely accepted textbook view of OR is that it is characterised by: (a) the application of a scientific method (b) interdisciplinary teams and (c) applied to complex problems. A central part of the scientific method, is the adoption of the following phases of OR (Decision) methodology (White 1975):

(a) Primary Problem Formulation Phase.

(b) Object System Model Phase.

(c) The Solution.

(d) Implementation.

In many ways, OR is closely related to the area of System Identification (SI) though it is seldom that this fact is referred to in the literature. SI is the determination of a system within a specified class of systems to which the system under test is equivalent, on the basis of input and output (Zadeh 1962).

Eykhoff (1974) suggests that the SI methodology consists of the following main steps:

(a) Selection of a model structure.

(b) Fitting of parameters to data.

(c) Verification and testing of model.

(d) Application of the model to its purpose.

Both OR \& SI apply the Scientific Method (hypotheses, experimentation, analysis). SI is concerned with physical and engineering systems that are usually subject to basic laws of physics. If a system is complex, then a black box approach can be used (e.g, using frequency response). OR is usually concerned with "Problem Solving" of complex socio-economic and management systems. One can argue that SI can be viewed as a special case of OR. OR can feed back experiences to help solve very complex physical/engineering systems (e.g., multiphase turbulent flow)(Kobbacy 1981).

Russell Ackoff has been advocating that OR should return to its original mission of serving executives rather than playing with mathematics and adopt a system orientation. He criticised OR in a series of papers on the grounds that OR provides solutions as opposed to "Synthetic Thinking" which aims at problem dissolution through design (Ackoff 1979a; Ackoff 1979b; Ackoff 2001). He also stressed that OR is preoccupied with efficiency, not effectiveness i.e., with doing things right rather than doing the right things. 
In contrast, the type of problems tackled in Artificial Intelligence are influenced by the direction set by its pioneers, McCarthy, Turing and Michie who set a challenge that can be summarised by the following quote from Turing's seminal paper (Turing 1950):

"I believe that at the end of the century the use of words and general educated opinion will have altered so much that one will be able to speak of machines thinking without expecting to be contradicted."

Thus early research in AI aimed to tackle problems that were considered to require intelligence, such as playing Chess. Despite initial excitement in the 1960's, the 1970's saw a quiet period for AI following the publication of a negative review of AI in the Lighthill report (1973). The 1980's saw a resurgent AI, with significant investment in Japan on the $5^{\text {th }}$ Generation Computer Systems project that aimed to develop parallel machines based on logic (Feigenbaum and Shrobe 1993), which was followed by a response from the UK with its Alvey programme (Oakley and Owen 2000) and sustained investment in a number of AI related projects by the European Strategic Programme of Research and Development in Information Technology (ESPRIT).

The majority of AI applications in the 80 s tended to be static and suffer from the Feigenbaum Bottleneck (Feigenbaum 1977) where both the development of the system and the quality of the end system were heavily dependent on the ability to elicit and represent expert knowledge. More recently, there has been a much greater focus on machine learning, with research aimed at improving decision tree learning algorithms, case based reasoning, genetic algorithms, neural networks and artificial immune systems.

Given these different goals and directions, it is not surprising that OR and AI have each resulted in techniques that have complementary properties. The following table summarises some of the characteristics of the OR/AI techniques and their differences.

\begin{tabular}{|c|c|}
\hline TECHNIQUES & PROPERTIES \\
\hline \multicolumn{2}{|l|}{ OPERATIONAL RESEARCH } \\
\hline Mathematical Programming & Optimisation \\
\hline Network Analysis/PERT/CPA & Project Planning \\
\hline Regression & Forcasting \\
\hline Queuing theory & Service models \\
\hline Simulation & What-if scenarios \\
\hline Maintenance Models & Planning replacement \\
\hline \multicolumn{2}{|l|}{ ARTIFICAL INTELLIGENCE } \\
\hline Logic and Theorem proving & Deduction and Inference \\
\hline $\begin{array}{l}\text { Production Systems, Semantic } \\
\text { nets,Frames, Objects }\end{array}$ & Representation of knowledge \\
\hline $\begin{array}{l}\text { Uncertainty Management (Bayes, Fuzzy } \\
\text { logic) }\end{array}$ & Capable of reasoning under uncertanty \\
\hline Case Based Reasoning & $\begin{array}{l}\text { Capable of reusing experience to solve } \\
\text { problems }\end{array}$ \\
\hline
\end{tabular}




\begin{tabular}{|l|l|}
\hline Data mining and Symbolic Learning & $\begin{array}{l}\text { Discovering new relationships and } \\
\text { models. Capable of aiding model and } \\
\text { knowledge acquisition }\end{array}$ \\
\hline Neural Networks, GAs & $\begin{array}{l}\text { Capable of learning how to classify, } \\
\text { cluster and optimise. }\end{array}$ \\
\hline Heuristic Searching methods (e.g. A*) & $\begin{array}{l}\text { Capable of finding good solutions quickly } \\
\text { in a large search space }\end{array}$ \\
\hline Intelligent Agents & $\begin{array}{l}\text { Capable of encapsulating a wide range of } \\
\text { properties including autonomous and } \\
\text { proactive behaviour. }\end{array}$ \\
\hline
\end{tabular}

Table 1: AI and OR techniques and their properties.

As the above table suggests, the range of techniques and their properties are quite different. As Fordyce, Norden and Sullivan (1987) point out, this is surprising since there is evidence that the Operational Research Community did have an early interest in the kind of problems that the AI community have addressed. Most notably, they refer to Simon and Newell's seminal paper "Heuristic Problem Solving: The next advance in operations research" that appeared in Operations Research as long ago as 1958. Fordyce et al. (1987) go on to explain two reasons why the OR community did not take up the challenges set by Simon and Newell: (a) a lack of computational power and memory that made it difficult for OR researchers to tackle problems that were "knowledge rich" and (b) there was a lack of "mathematical niceness" that OR practitioners were trained to require.

Fortunately, the AI community had its own reasons for studying and solving the kinds of problems that together with the traditional OR discipline has led to a significant amount of research since the 1980s. The following sections present the results of the survey which enable reflection upon the major areas of effort, their effectiveness and where furture research should focus.

\section{SURVEY AND REPRESENTATIVE RESEARCH}

This section presents the survey examining the use of AI techniques in various parts of operations management. The framework for the survey has evolved from that used by the authors in their previous surveys. In the 1998 survey, the authors extended Schroeder's (1993) framework which defined four major categories for decisions, namely: process, quality, capacity and inventory. In the 2000 survey, the focus was on applications in manufacturing and used Rao et. al. 's (1993) framework, which has the following six areas: (a) design, (b) scheduling, (c) quality management, (d) maintenance $\&$ fault diagnosis, (e) process planning and (f) process control. These categories worked well in the 2000 survey and initially, they were adopted for this survey but extended to include service as well as manufacturing operations. An additional category for knowledge management, which was expected to be a growth area, was also added. However, as the survey proceeded, these categories seemed to be too fine, making it difficult to distinguish papers between some of the related categories. In particular, and perhaps not surprising in hindsight, papers on process planning, control, inventory management and supply chain management were closely related, and papers on quality, maintenace and fault diagnosis were also related. Surprisingly, there were hardly any papers on the use of AI techniques in knowledge 
management, making its use as an additional category redundant. Thus, although the use of the seven categories seemed appropriate initially, in practice, it made better sense to merge the closely related areas to ensure that the categorisation of papers was sufficiently accurate and there were an adequate number of papers in each category for any trends to be meaningful. Hence, for the purposes of this survey, the following four major categories were utilised:

- Design

- Scheduling

- Process Planning and Control (including inventory and supply chain management)

- Quality, Maintenance and Fault Diagnosis

As indicated in Table 1 above, there are several categories of AI techniques, some well established and others, such as dynamic Bayesian networks and temporal data mining, still growing in importance in operations management. The techniques we selected to focus on were those that would enable a ten year survey: Case Based Reasoning (CBR), Genetic Algorithms (GAs), Neural Networks (NN), Knowledge Based Systems (KBS), and Fuzzy logic, all of which have been established for over a decade. Data mining was also considered as a possible area but, once we decided to have the categories of NN, and GAs, there were very few papers applying techniques such as association rule mining in operations management to produce any sensible trends over the last decade. As well as the established AI techniques, we were also interested in the use of a combination of the AI techniques and hence added a category, called hybrid.

The methodology adopted was simple and involved using fairly obvious keywords to search the Science Direct Database to identify references in chronological order. The number of papers considered was large and the process of filtering and classification of the papers was time consuming, resulting in the classification of over 1200 papers. Each identified paper was then classified according to the area and technique used. There are three important points to note about the classification process:

- Although most of the classifications were reasonably clear, some inevitably required our judgement. For example, some of the papers would mention design in general terms several times but would not be about design processes or about the design of products.

- Having identified maintenance as part of a separate area, papers on scheduling maintenance activity were categorised under maintenance and not scheduling.

- Papers that used a hybrid approach were not double counted, so for example, papers that used GAs and NNs together were counted just once, under the hybrid category.

The following subsections present an overview of the use of AI techniques in each of the four areas of operations management by citing representative and innovative work. Some relevant papers that appeared, or are in press in 2005 are included in the description, though later, they are omitted from the statistics when considering the 10 year trends. Section 4 presents an analysis of the results and discusses current and future trends. 


\subsection{DESIGN}

\subsubsection{CBR and Design}

Case Based Reasoning (CBR) aims to provide a memory of past experience in the form of reusable cases. CBR is therefore very appropriate for reusing past designs, resulting in savings in comparison to design from first principles. To date, the majority of systems utilizing CBR are in retrieving past designs, such as designs of reactive distillation systems (Avramenko et al. 2004), offshore well designs (Mendes et al. 2003), hydraulic production machine design (Vong et al. 2002), design of antibiotic therapy regimens for patients in critical care (Heindl et al. 1997), ship designs (Lee Dongkon and Lee Kyung-Ho 1999), designs of low power transformers and design of software (Paek et al. 1996; Praehofer and Kerschbaummayr 1999).

Many design problems involve trying to optimise parameters or a trade-off between parameters in order to meet the problem requirements. CBR has been used in a few such applications, including design of materials to meet product requirements (Amen and Vomacka 2001; Mejasson et al. 2001), and the design of chemicals that meet safety and environmental requirements (King et al. 1999).

Given the general success of the use of CBR that has been reported in conferences such as the International Conference on CBR, it is perhaps a little surprising that there hasn't been a significant growth in their use for design. Applications that aim to utilize past design strategies, promote discovery of designs and innovation appear not to have materialized. Though there are some interesting papers in the 1990's on the use of CBR for inventive design (Ishikawa and Terano 1996), the process of aiding innovation (Faltings and Sun 1996), and on creative design (Kolodner and Wills 1996) these studies appear not to have been followed up.

One reason for this lack of growth might be that most applications of CBR rely on the availability of very similar cases and leave the subsequent adaptation of the retrieved design to the human designer. More research on adaptation may therefore be needed if the range of applications that would find CBR useful is to increase.

\subsubsection{GAs and Design}

A major strength of GAs is their ability to evolve near optimal solutions to non-linear optimisation problems. Hence they have been widely used in the design of structures and materials where strength and safety requirements that are non-linear need to be met. Examples of applications in this area include the design of multi-storey steel frames (Kameshki and Saka 2001; Kameshki and Saka 2003), their use to design alloys to meet user requirements (Kulkarni et al. 2004), and their use to design reinforced concrete (Leps and Sejnoha 2003; Rafiq and Southcombe 1998).

GAs have also been advocated for drug design though, surprisingly, only a few papers have been published in this area, including their use in tools for drug design (Hou and Xu 2001) and some review papers (Park et al. 2004; Terfloth and Gasteiger 2001). 
The use of GAs to meet various criteria including safety requirements has been reported in several studied (Cantoni et al. 2000; Jo and Gero 1998; Matsuzaki et al. 1999; Osman et al. 2003).

An interesting use of GAs is in providing designers with a tool in which they can use GAs to explore alternative designs interactively by guiding the evolution process. Examples include the aesthetic design of dams (Furuta et al. 1996), design of fashionable clothes (Kim and Cho 2000) and using user guided breeding in CAD (Graham et al. 2001). 


\subsubsection{Neural Networks and Design}

The primary use of artificial neural networks in the last decade has been in drug design and design of materials. Drug design represents more than a third of the neural network applications in design. Many of these focus on using the predicative power of the backpropagation algorithm to help quantify structure-activity relationships (Kovesdi et al. 1999; Polanski et al. 2002; Polanski et al. 2000; So and Karplus 1997; Terfloth and Gasteiger 2001). Other uses include optimising release of drugs such as aspirin (Ibricacute et al. 2003; Sun et al. 2003; Wei et al. 2001) and the pursuit of therapies for AIDS (Cai et al. 1998; Sardari and Sardari 2002).

Applications in engineering design also represent about twenty percent of the uses of neural networks in design, though the range of applications is more variable. Applications include designing concrete structures (Adeli and Park 1995; Cladera and Mari 2004; Deng et al. 2003; Dias and Pooliyadda 2001; Hadi 2003), design of coldform steel (Adeli and Park 1995; El-Kassas et al. 2001; El-Kassas et al. 2002; Karim and Adeli 1999) and the design of polymers (Zhang and Friedrich 2003).

Novel applications include the use of NNs to aid design by features in computer integrated manufacturing (Ding and Yue 2004), design of catalysts (Huang et al. 2001; Huang et al. 2003; Liu et al. 2001; Sasaki et al. 1995) and the design of digital aids that provide reminders for people with dementia (Mihailidis et al. 2001).

\subsubsection{KBS and Design}

Despite scepticisms about the use of expert systems or KBS in the early 1980's, the volume of publications on the successful application of KBS is impressive. The majority of applications are in engineering and construction. These include a diverse range of systems such as those for the design of automotive engine components (Sapuan et al. 2002), design of elevator systems (Motta et al. 1996; Rothenfluh et al. 1996) design of digital filters (Cappellini et al. 1995), bridge design (Moore et al. 1997; Shiva Kumar et al. 1995), design of offshore structures (Soh and Miles 1995), design of water retaining structures (Chau and Albermani 2003), design of relief vents for dust explosions (Vadera et al. 2001), layout of ship engine rooms (Lee et al. 1998) and several systems that aid design of buildings (Gonzalez-Uriel and RoanesLozano 2004; Mohamed and Celik 2002).

There are also several KBS systems that support concurrent engineering, a process that looks at the full design and development cycle of products (Laring et al. 1996; Xue et al. 1999; Zha and Du 2002). However, given the importance of concurrent engineering, it is surprising that there are few follow up studies post-2002.

There are fewer applications of KBS in design outside engineering, but include a system for the design of dentures (Davenport et al. 1996), use of KBS for curriculum design (Wilcox 1996) and a system to support the design of data bases (Storey et al. 1998). 


\subsubsection{Fuzzy Logic and Design}

Design is usually based on imprecise criteria and the use of fuzzy logic therefore offers very relevant methods to enable optimisation of parameters to meet requirements.

Feng (2001) (Feng et al. 2001) studies how requirement can be mapped to fuzzy relations. Tang et al. (2002) and Karsak(Karsak 2004) develop systems that enhance Quality Function Deployment (QFD) with fuzzy linguistic terms to represent design requirements and which enable assessment of the extent to which design requirements are met. Design of products to meet personal requirements such as look, feel and taste represents an interesting use of fuzzy logic that is explored by Cai et al. (2003) for product appearance, by Park and Han (2004) for the design of office chairs, by Hanson (Hanson et al. 2003) for design of car interiors and by Sigman and Liu (2003) for modelling non-functional requirements for software design and development.

\subsubsection{Hybrid Approaches in Design}

The FL/NN combination is the most popular hybrid combination for design. Hsiao and Huang (2002) use a FL/NN approach to establish relationships between productform parameters and image descriptors which can then be used by designers to generate products meeting desirable customer requirements. Sun (2000) uses a combined NN and fuzzy inference approach to rank alternative designs based on customer requirements. Zha and Lim (Zha and Lim 2003) use a fuzzy neural network that is capable of taking account of operator posture and movement for the optimal design of manual assembly workstations.

Though not as popular, the GA/NN combination has also been used in design, for example, in the design of catalysts, where a NN is used to model interactions and a GA is used to design and optimise a catalyst (Huang et al. 2003).

Despite the popularity of KBS in design, they are rarely used in combination with other techniques for applications in design. One of the few studies that utilises the KBS/NN combination is by Zakarian and Kaiser (1999) who use it to support optimisation of parameters in computer-aided design.

\subsection{Quality, Maintenance and Fault Diagnosis}

\subsubsection{CBR in Quality, Maintenance and Fault Diagnosis}

The survey did not find any published papers in quality management or maintenance that use CBR. Only a few publications were found in fault diagnosis, including two papers on the use of CBR in locomotive diagnostics: (Varma and Roddy 1999) and (Vingerhoeds et al. 1995). Xia and Rao (1999) argued for the need to develop dynamic CBR, which introduces new mechanisms such as time-tagged indexes to help solve problems that need to take into account system dynamics and fault propagation phenomena. Cunningham et al.(1998) describe an incremental CBR mechanism that can initiate the fault diagnosis process with only a few features. 


\subsubsection{GAs in Quality, Maintenance and Fault Diagnosis}

Applications of GAs in quality management are limited to a few examples, including the development of a river water quality management model (Kapanoglu and Miller 2004), a management system for damaged concrete bridges in Japan (Miyamoto et al. 2001) and in the more classical quality management area of the design of control charts (Celano G. and Fichera S. 1999).

GAs are more popular in maintenance because of their robust search capabilities that help reduce the computational complexity of large optimisation problems. Thus there are applications in nuclear power plants (Pereira and Lapa 2003), and in the area of safety related systems to assure a high level of reliability (Martorell et al. 2004). Preventive maintenance scheduling optimisation is another popular area where GAs have been used and includes the areas of chemical process operations (Tan and Kramer 1997), nuclear systems (Lapa et al. 2000), power systems (Huang 1998), single product manufacturing production line (Cavory et al. 2001) and mechanical components (Tsai et al. 2001).

GAs have attracted moderate interest over the past decade for fault diagnosis, with applications in nuclear power plants (Yangping et al. 2000) and electrical distribution networks (Wen and Chang 1998).

\subsubsection{NNs in Quality, Maintenance and Fault Diagnosis}

NNs are the most popular AI technique applied in the areas of quality, maintenance and fault diagnosis. In quality management, there has been a few publications on predicting and management of quality of river water, watershed, groundwater and costal water (Aguilera et al. 2001; Chen et al. 2004; Hong and Rosen 2001). Other applications include the use of NNs to predict performance of design-build projects (Ling and Liu 2004) and the management of secure communication systems (Karras and Zorkadis 2003).

NNs have many applications in the area of predictive maintenance and more specifically in condition monitoring. An interesting application, developed by Garcia et al. (2004), uses NNs to aid tele maintenance, where staff can carry out the work remotely and in collaboration with other experts. Other applications of NNs in condition monitoring include the work of Bansal (Bansal et al. 2004)et al. on machine systems, Booth and McDonald (1998) on electrical power transformers, Luxhoj (Luxhoj 1998) on turbine flow-meters and Spoerre (1997) on bearings. Shyur et al. (1996) use NNs to predict component inspection requirements for ageing aircraft and Eldin and Senouci (Eldin and Senouci 1995) use NNs for the condition rating of joint concrete pavements.

As mentioned earlier, NNs are very popular for fault detection and diagnosis. They have been discussed since the late 1980s for model based fault detection and isolation, particularly when analytical models are not available. In an early review paper on use of AI in fault diagnosis, Frank and Koppen-Seliger (1997b) indicated that the goal of fault detection is to detect the fault and its causes early enough to avoid overall system failure. They defined 3 steps for fault detection (i) residual generation, i.e., 
generation of a signal that reflects the fault, (ii) residual evaluation, i.e., the logical decision making on the time of occurence and location of the fault and (iii) fault analysis i.e., determination of the type of fault, its size and cause. For using NNs in fault diagnosis, they have to be trained for both residual generation and evaluation using collected or simulated data for the former and residuals in the latter. The major difficulty of using NNs in fault detection is the lack of analytical information on the performance, stability and robustness of the network.

There has also been a strong interest in using NNs for fault diagnosis in the chemical process industry, for example in fault diagnsis of packed towers (Sharma et al. 2004), complex chemical plants (Ruiz et al. 2001b), and batch processes (Scenna 2000).

\subsubsection{KBS in Quality, Maintenance and Fault Diagnosis}

There is continued growth and interest in the applications of KBSs in quality management. Chin et al(Chin et al. 2003). have developed a knowledge based self assessment system to measure organisational performance based on a renowned Business Excellence Model and Stein et al. (2001) have developed a KBS to support implementation of the American Disability act in a University. Other applications include use of KBSs for evaluating watershed processes with respect to ecological states (Reynolds et al. 2000), quality assessment in the food industry (Stein and Miscikowski 1999) and for auditing processes in quality assurance systems (Bayraktar 1998).

We found only a few papers in the area of KBS in maintenance management in the past decade. Of particular interest is the study by de Brito et al. (de Brito et al. 1997) which developed a prototype system for optimising the inspection, maintenance and repair strategies for bridges.

There have been many applications of KBS in fault diagnosis, including rotating machinery (Yang et al. 2005), induction motors (Acosta et al. 2005), CNC machinetools (Leung and Romagnoli 2002), industrial gas turbines (Milne et al. 2001), reactors (Varde et al. 1998), electrical power distribution systems (Baroni et al. 1997; Teo and Gooi 1997), monitoring green house sensors (Beaulah and Chalabi 1997), coal washing plant (Villanueva and Lamba 1997), chemical processes (Batanov and Cheng 1995; Joo Mo et al. 1997; Nam et al. 1996), and in robotic systems (Patel et al. 1995).

\subsubsection{Fuzzy Logic in Quality, Maintenance and Fault Diagnosis}

Apart from a couple of papers on identification of river/stream water quality, we found no other publications for FL in quality management. Similarly we located very few papers on using FL in maintenance, including the work of Al-Najjar and Alsyouf (Al-Najjar and Alsyouf 2003) on using fuzzy multiple criteria decision making and that of Jeffries et al(Jeffries et al. 2001). which presents a fuzzy approach to condition monitoring of a packaging plant. 
Using FL in fault diagnosis involves fuzzifying residuals, evaluating residuals using inference and then defuzzifying them (Frank and Koppen-Seliger 1997a). There are a wide range of application areas for FL in fault diagnosis. These include fault diagnosis of thrusters for an open-frame underwater vehicle (Omerdic and Roberts 2004), railway wheels (Skarlatos et al. 2004), Chemical processes (Dash et al. 2003; Ruiz et al. 2001a), analog circuits (El-Gamal and Abdulghafour 2003) and rolling element bearings in machinery (Mechefske 1998) .

\subsubsection{Hybrid Approach in Quality, Maintenance and Fault Diagnosis}

There are several applications that utilise a combination of CBR and KBS systems in quality. Humphreys et al. (2003) combine CBR, KBS and multi-attribute analysis (MAA) to evaluate supplier environmental management performance. CBR/KBS hybrid systems are utilised by Cheung et al. (2003) for performance management and monitoring in customer services, by Lee et al. (1999) in clinical incident management to improve quality of care and Foong et al. (1997) uses CBR/KBS in intelligent help desk fault management.

There are only a few studies that make use of hybrid systems for fault diagnosis. Amongst these, the FL/KBS combination is the most common, including the work of Zhao and Chen (2001) on diagnosing concrete bridge deterioration, Ortega (Ortega and Giron-Sierra 1998)and Giron-Sierra's research on automated servicing of a space station and Tarifa and Scenna's (2004; Tarifa and Scenna 2004) work on fault diagnosis. Jota et al. (1998) used neuro-fuzzy techniques and a KBS for fault detection in service power transformers

Yang et al. (Yang et al. 2004) (2004) integrated NN with CBR to enhance fault diagnosis by using CBR to search for similar previous cases. Ozyurt et al. (1998) have developed a hybrid symbolic-connectionist machine learning approach for fault diagnosis in a hydrocarbon chlorination plant. Frank et al. (1997a) and Tyan et al. (1996) have developed hybrid NN/ Fuzzy logic systems for fault diagnosis. Luxhoj and Williams (1996) present a hybrid NN/ KBS DSS for aircraft safety inspection.

\subsection{SCHEDULING}

\subsubsection{CBR in Scheduling}

The primary use of CBR in scheduling is in job shop scheduling and is typified by the CasePlan (Dzeng and Tommelein 2004) and CABIN (Miyashita et al. 1996) systems. Both systems show the feasibility of retrieving similar past cases and adapting them to solve job shop scheduling problems.

\subsubsection{GAs in Scheduling}

The last decade has focused on six major areas of applying GAs to scheduling problems: job shop scheduling, scheduling of tasks on multi-processors, labour scheduling, scheduling vehicles and forest management. 
The development of products requires sequencing of jobs to machines in a way that minimizes tardiness and makespan. The last decade has seen many attempts at using GAs for single products (Adamopoulos and Pappis 1998; Caraffa et al. 2001; Iyer and Saxena 2004; Knosala and Wal 2001; Kurz and Askin 2004; Mattfeld and Bierwirth 2004; Nearchou 2004; Wang and Xue 2002), and for multi-objective problems (Cardon et al. 2000; Oh and Wu 2004). Determining an opitimal batch size can also be a significant factor for production lines, and some authors, notably (Khouja et al. 1998; Sarker and Newton 2002), use GAs to address this problem.

The advent of parallel machines and multi-processor computers results in analogous problems to job shop scheduling, except that tasks need to be allocated to different processors and throughput needs to be optimised subject to the availability of processor and memory constraints. Aguilar and Leiss (2004) study this problem for shared memory systems and several other authors propose alternative approaches for scheduling processes on multiprocessors (Ahmad and Dhodhi 1996; Oh and Wu 2004; Tsuchiya et al. 1998). Braun (Braun et al. 2001) presents a comparison of eleven heuristics for scheduling tasks onto distributed computing systems.

The problem of making the best use of staff with different experience and capabilities is a key to the success of any organization, whether it is in the health service, academia or production. The studies reported by Cai and Li (2000) and Easton and Mansour (1999) consider this problem in a general context, while Aickelin and Dowsland(Aickelin and Dowsland 2004) (2004) develops a GA based system for scheduling of duties for nurses.

Vehicle scheduling problems often go beyond minimizing distance, incorporating different service level requirements for different customers and levels of costs. Baita (Baita et al. 2000)presents the limitations of a traditional approach and compares it to the use of GAs. Malmborg (1996) presents the use of GAs to meet service levels, and Taniguchi and Shimamoto (2004), present a GA based scheduler for the dynamic scheduling of traffic that uses real time information.

Although not as extensively used as the in the above areas, the use of GAs in management of forests and irrigation is interesting. Moore et al. (2000) use GAs to examine the effects of different policies on the populations of birds and extinction rate. Ducheyne et al. use GAs to assess the effects of different management policies on the even-flow forest management problem.

\subsubsection{Neural Networks in Scheduling}

Of the different neural network algorithms, the Hopfield and Boltzman machines are considered the most suitable for optimisation problems. The Hopfield model is the most widely used in scheduling, with applications in job shop scheduling (Foo et al. 1995), its use to schedule generators (Dillon and O'Malley 2002) and to schedule the broadcasting of packets in a multihop packet radio network (Li-Chiun Wei and Chang 1997). Though the Boltzman machine is regarded as an improvement over the Hopfield model, in that it avoids local minima, we did not find any papers that utilise them directly for scheduling. 
Though less suitable for optimisation, feed forward neural networks have also been used. For example, Ben-Nakhi and Mahmoud (2002) uses feed forward neural networks to predict the optimal settings for air conditioning so as to minimise energy utilisation.

An interesting use of feed forward networks is to aid scheduling by predicting parameters such as tardiness and lead times and then using higher level search procedures that utilise this capability to evaluate alternative proposed solutions and optimise schedules (Fonseca and Navaresse 2002; Park et al. 2000).

\subsubsection{KBS in Scheduling}

The use of KBS in scheduling is small in comparison to the use of GAs. Example uses include providing construction managers with a tool for exploring alternative schedules that take into account resources, material selection and costs (Mohamed and Celik 2002), its occasional use in job shop dynamic scheduling that aims to achieve load balancing on machines for a flexible manufacturing plant (Zhang and Chen 1999), the scheduling of railway freight loadings (Geng and Li 2001) and determining schedules of breathing pressures for pilot masks based on antropometric and physiological information so that pilots don't fall unconscious (Yeow et al. 2002).

\subsubsection{Fuzzy Logic in Scheduling}

In most practical scheduling problems, due dates, processing times and even constraints are not precise and hence fuzzy logic and set theory have been widely used in scheduling and project planning. Several authors have developed algorithms for the single machine job shop scheduling problem with fuzzy due dates and processing times, including (Adamopoulos and Pappis 1996; Chanas and Kasperski 2001; Ishii and Tada 1995; Lam and Cai 2002; Muthusamy et al. 2003; Sung and Vlach 2003; Wang et al. 2002). A useful theoretical result that shows the difficulty of the problem is that minimizing the maximal expected tardiness can be solved in polynomial time whilst minimising the expected maximal tardiness remain NP-Hard when due dates, processing time and tardiness are fuzzified (Chanas and Kasperski 2003).

In the area of project management, Hapke and Slowinski (1996) presents an extension of an existing method for setting priorities for project scheduling under constraints on resources, Wang(Wang 2002) presents a fuzzy beam based search algorithm to develop an algorithm that aims to minimize the risk of a schedule and satisfy temporal constraints.

\subsubsection{Hybrid in Scheduling}

GAs are good at optimisation, NN's are good at classification or estimation and fuzzy logic is good at modelling uncertainty. Hence combinations of these techniques provide greater power and flexibility in solving scheduling problems. Several authors use GAs to carry out an intelligent search by proposing alternative schedules and then using a NN to assess the quality and fitness of the schedule. A GA then combines the best solution using mutation and crossover operators and then repeating the process to 
evolve a near optimal solution (Dagli and Sittisathanchai 1995; Lee and Dagli 1997). Fuzzy logic and GAs have been combined effectively for scheduling, where the variables such as due date, processing times and tardiness are modelled using fuzzy sets and the GAs optimise over a fuzzy objective function that minimises tardiness (Kim et al. 2003; Peng and Liu 2004; Sakawa and Kubota 2000; Tsujimura et al. 1995).

\subsection{Process Planning and Control}

\subsubsection{CBR in Process Planning and Control}

Only a few papers were found on applications of CBR in process planning. These include the work of Yuen et al(Yuen et al. 2003). to develop a generic computeraided process planning support system, Lei et al. (2001) on applying CBR to cold forging process planning and Chang et al. (Chang et al. 2000) on indexing and retrieval in machining process planning. Park et al. (1998) discuss the use of CBR in process control of complex production processes.

In supply chain management, $\mathrm{CBR}$ has been used to develop an intelligent customersupplier relationship management system Choy et al. .

\subsubsection{GAs in Process Planning and Control}

GAs have been used in several studies in process planning and optimisation (Drstvensek et al. 2004; Lee et al. 2002), which in a way overlaps with the scheduling area of application. Senin et al. (2000) investigate the application of GAs to concurrent assembly planning. Another interesting area for using GAs in process planning is in setting machinaries e.g. multi-pass face milling (Shunmugam et al. 2000) and optimal depth of cut in multi-pass turning (Bhaskara Reddy et al. 1998). Vancza and Markus (1996) present a feature-based process planning model which optimises manufacturing costs using a GA.

There are numerous applications of GAs in process control including the elevator cars routing problem (Tyni and Ylinen 2005), control of phosphate processing plant (Karr 2003), control strategy of complex spinning (fibre-yern) production process (Sette et al. 1998) and in calibrating computer models of mineral processing equipment (Karr and Yeager 1995).

There has been increasing interest in using GAs as an optimisation technique in inventory management. GAs have been used for allocation of shelf space (Hwang et al. 2005), capacitated lot-sizing problem (Xie and Dong 2002) and the inventory management of lumpy demand items (Mak et al. 1999). The joint replenishment problem (JRP), which deals with multi-item inventory problems, has been studied using GAs by Chan et al. (2003) for multi-buyer situations.

There has been recent interest in applying GAs in reverse logistics and multi-echelon supply chains (Liang and Huang 2005; Lieckens and Vandaele 2005). 


\subsubsection{NNs in Process Planning and Control}

There has been only a small number of publications on the use of NNs in process planning of manufacturing systems. In order to carry out process optimisation, Chambers and Mount-Campbell (2002) develop a neural network metamodel of the components of a system and the entire system is then modelled by interconnecting the NN metamodels. Monostori et al. (2000) propose the use of a NN processs model to satisfy requirements of machining at different levels and stages. Santochi and Dini (1996) use NNs in selection of technological parameters of cutting tools.

NNs are a very popular technique used in process control to establish process models. Research projects in recent years have focused on the use of neural networks as a tool for system identification that can deal with nonlinearity (Lennox et al. 2001). The main application areas are chemical and process industries and manufacturing. Examples of recent applications include a semi-batch polymerization process ( $\mathrm{Ng}$ and Hussain 2004), thermal food processing (Torrecilla et al. 2004), fermentation processes (Lopes and Menezes 2004), chemical reactors (Yu and Gomm 2003), basic oxygen steel making (Cox et al. 2002) and injection molding (Kenig et al. 2001). Lennox et al. (2001) investigate the industrial application of NNs in the area of process monitoring and control. Azlan Hussain (1999) reviews the applications of NNs in chemical process control. An interesting area in process control, which overlaps with quality control, is the use of statistical process control (SPC) to identify process problems. There has been a number of publications on the use of NNs in SPC including the studies by Al-Assaf (2004), Zorriassatine et al. (2003) and Guh et al. (1999).

NNs are used to solve a variety of inventory problems in industry. Forest characteristics, tree mortality and predicting forest cover types were studied by Moisen and Frescino (Moisen and Frescino 2002), Hasenauer et al. (2001) and Blackard and Dean (1999) respectively. Wang (2001) uses NNs in yield management to adjust price in order to maximise profit in the airline and hotel industries. Baker (1999) studies the assortment problem where demand for any size that is not stocked must be met by supplying the nearest acceptable size. Partovi and Anandarajan (2002) use NNs to carry out ABC inventory classification.

\subsubsection{KBS in Process Planning and Control}

KBSs have some applications in manufacturing process planing. Zhao et al (Zhao et al. 2002) describes the integration of KBS with a CAD system and Arezoo et al. (2000) present a KBS both for selection of cutting tools and conditions for turning operations. Jiang et al. (1999) use an intelligent KBS to generate optimal manufacturing process plans from CAD drawings. Shehab and Abdalla (2001) develop a fuzzy logic based knowledge representation approach that helps in estimating cost modelling of machining processes. 
Applications of KBS to process control include the development of a reflow soldering control system (Tsai 2005), control of industrial wastewater detoxication plants (Szafnicki et al. 2005), bioprocess control (Hrncirik et al. 2002) and multivariate PID control (Ho et al. 1998) .

In the area of inventory management, work was developed in the areas of forest ecosystem management (Nute et al. 2004) and impact from Chernobyl on Spanish marine environment (Molero et al. 1999).

In supply chain management, NNs have been used together with autoregressive methods for improving forecasting and reducing inventory levels and sales failures (Aburto and Weber 2005). Hsieh and Tien (Hsieh and Tien 2004) use Kohonen selforganising maps for the uncapacitated location allocation problem and compare it with the use of simulated annealing.

\subsubsection{FL in Process Planning and Control}

Karr (1996) discusses adaptive process control and the role of the various AI techniques. Fuzzy Logic is used to manipulate the problem environment, GAs search for more efficient fuzzy membership functions than those used by FL and NNs are used to simulate the problem (as a system identification tool, see section 3.4.3). As such the extensive use of FL in process control (like NNs) is not surprising. Indeed the combined use of FL with NN in particular and GA to a lesser extent is expected.

There are many application areas for FL in process control including the control of gari fermentation plant (Odetunji and Kehinde 2005), basic oxygen furnace (Kubat et al. 2004) cheese ripening (Perrot et al. 2004), spindel torque for CNC machining (Liang et al. 2003), food frying (Rywotycki 2003), flotation column (Carvalho and Durao 2002), combustion control of stoker-fired boilers (Li and Chang 2000) and anaerobic digester in a fluidized bed reactor (Estaben et al. 1997).

Samanta and Al-Araimi (2001) present an inventory model based on FL which simulates the DSS to maintain the inventory of a finished product system at the desired level. Bogataj and Usenik (2005) formulated the problem of supply chain coordination using fuzzy sets and compared the outcomes with analytical results. Lin et al.(2005) use FL for developing a supply chain agility measure and apply it to evaluate the agility of a Taiwanese company.

\subsubsection{Hybrid in Process Planning and Control}

There are several hybrid systems that use the FL/GA combination for planning and control, including the work of Acosta and Todorovich (2003) on induction motors, Guillaume and Charnomordic(Guillaume and Charnomordic 2001) in food industry databases, Karr and Freeman(Karr and Freeman 1997) on spacecraft autonomous rendezvous and Tarng et al. (1996) in turning operations. Other hybrid applications include a NN/GA system for fruit-storage control (Morimoto et al. 1997) and a multiple hybrid system for a cryogenic cooling plant (Linkens et al. 2000). The 
FL/GA combination has also been used for modelling supply chains where FL is used to determine supply chain uncertainty and a GA is used to determine up to inventory level (Wang and Shu 2005).

Uses of $\mathrm{KBS} / \mathrm{FL}$ is also very popular in process control. Examples include their use in situ groundwater bioremediation (Hu et al. 2003), a system which utilises a FL rulebased inference engine to provide overall control for a bottling plant (Jeffries et al. 2003) and knowledge-based supervisory control of a fish processing workcell (de Silva and Wickramarachchi 1998).

Hybrid NN/FL systems have several applications in process control including looper tension control in rolling mills (Janabi-Sharifi 2005), industrial wastewater treatment (Chen et al. 2003), logic control for arc welding (Di et al. 2001), on-line tool wear estimation (Kuo 2000) and manufacturing process control (Kuo and Cohen 1998). Morimoto et al. (1997) present a NNs/ GA hybrid approach for optimal control of a fruit-storage process.

Ming and Mak (2001) use a hybrid GA/NN approach to study tolerance allocation and manufacturing operations selection in process planning.

$\mathrm{Du}$ and Wolfe (1997) present details of the implementation of NN/FL systems in industry including inventory. In supply chain management, a hybrid CBR/NN approach has been used for benchmarking suppliers in outsource manufacturing (Choy et al. 2002) and for supplier-relationship management (Choy et al. 2003)

Examples of multiple hybrid systems include the use of KBS/FL and NNs in control of communication systems (Guyot et al. 2004) and aquaculture (Lee 2000), and the use of FL/NN/GA in automation and control of reverse osmosis plants (Zilouchian and Jafar 2001) and cryogenic cooling plant (Linkens et al. 2000). 


\section{ANALYSIS, CURRENT TRENDS AND DISCUSSION}

We now discuss the results obtained with respect to the questions raised in the introduction, namely:

(a) What is the current direction of research on applying AI techniques in Operations Management?

(b) What are the trends in terms of utilising particular AI techniques for subproblems in Operations Management?

(c) What should the future direction of research be?

Rather than attempting to answer these questions by using just the publication rates in some absolute fashion, it is more interesting and revealing to analyse the publication rates with respect to what we might have expected given the known characteristics of the AI techniques and problems. Our personal view of the regions of applicability of OR and AI techniques relative to the decision making level and the extent to which a problem is structured is summarised in Figure 1.

\section{Executive}

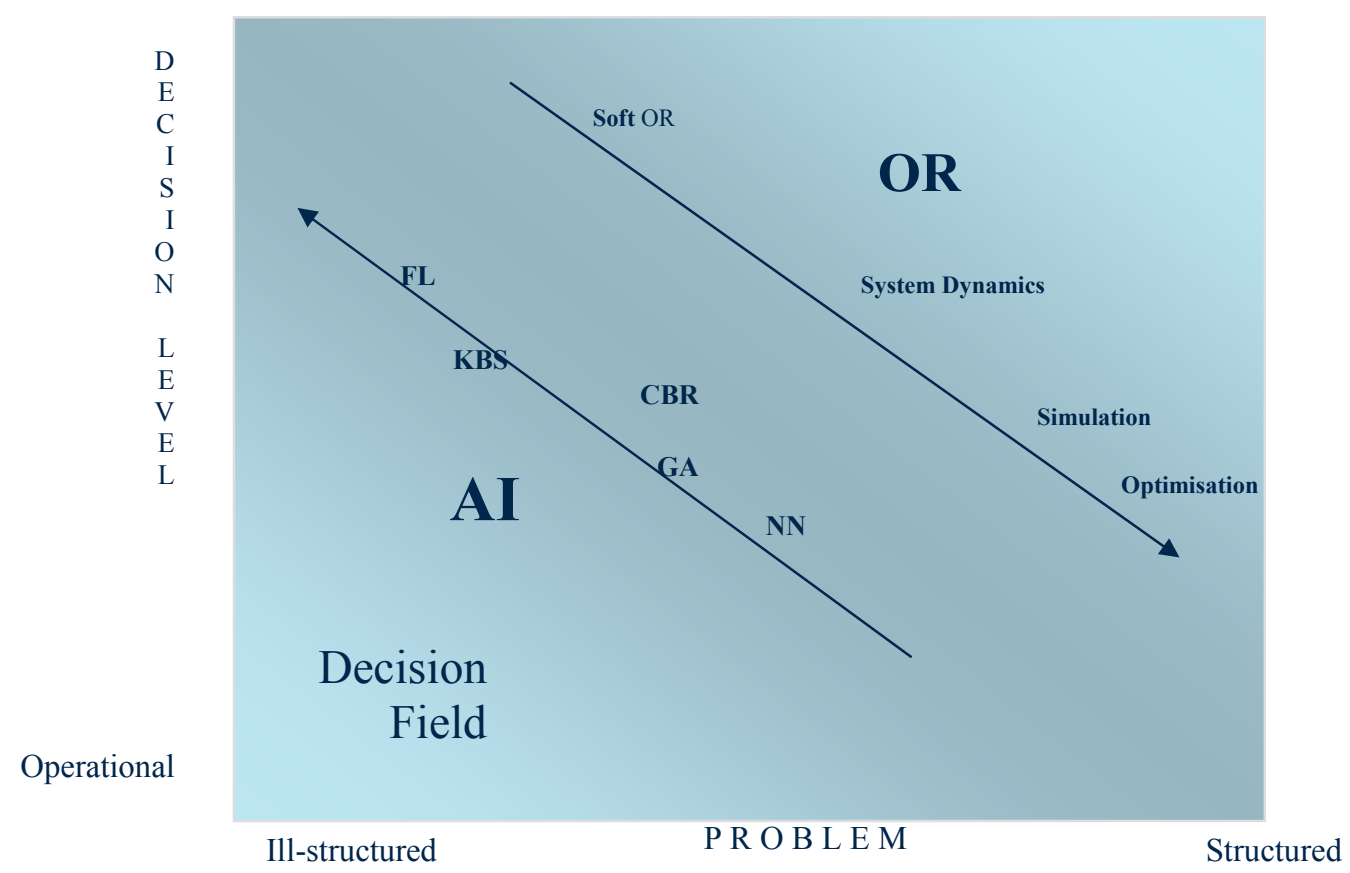

Figure 1: $\quad$ AI and OR Techniques with respect to decision levels and how well a problem is structured and defined.

As problems become more strategic and less well defined, one would expect greater uncertainty in the specification and solution process involved. One would therefore expect fuzzy logic to be more applicable in such circumstances and, hence its position towards the top left of Figure 1. Likewise, knowledge based systems have proved to 
be very useful for problems that do not necessarily have analytical solutions and can be expected to be placed more towards the top left hand quarter of the Figure 1. Case based reasoning systems retrieve similar past cases to solve a current problem, making them suitable for problems that range from being semi-structured to those that are less structured, hence their more central position. Neural networks and Genetic Algorithms both require identification of a set of parameters and are particularly good for more structured problems that involve classification and clearly defined optimisation problems; hence their position towards the bottom right of the graph.

Where do the four areas of operations management fit on Figure 1? Design is probably the least well structured, often requiring creative thinking to meet vague design goals and is therefore most towards the top left hand corner of the figure. Scheduling is more operational in nature but real-world scheduling involves vague starting times, and goals that are time and context dependent. Hence Scheduling problems are more towards the bottom left hand corner of the diagram. Process planning, control, quality and maintenance tend to be operational and are generally well defined, so we would expect them to be more at the bottom right hand corner of this diagram. How do these expectations compare with the number of publications for each problem area/AI technique? The following table is organised so that the shaded rows and columns correspond to the four corners of Figure 1. That is, if our expectations were followed perfectly, then we would expect highest weights in the top left hand and bottom right hand corners of the table.

\begin{tabular}{|l|c|c|c|c|c|c||c|}
\hline & $\begin{array}{l}\text { Fuzzy } \\
\text { Logic }\end{array}$ & KBS & CBR & GAs & NN & Hybrid & Total \\
\hline Design & 44 & 129 & 53 & 130 & 101 & 52 & 509 \\
\hline Scheduling & 71 & 32 & 7 & 109 & 19 & 42 & 280 \\
\hline $\begin{array}{l}\text { Process Planning } \\
\text { and Control }\end{array}$ & 37 & 25 & 4 & 28 & 97 & 45 & 236 \\
\hline $\begin{array}{l}\text { Quality \& } \\
\text { Maintenance } \\
\text { and Fault Diagnosis }\end{array}$ & 16 & 26 & 6 & 36 & 93 & 20 & 197 \\
\hline Total & 168 & 212 & 70 & 303 & 310 & 159 & 1222 \\
\hline
\end{tabular}

Table 2: Number of publications from 1995 to 2004.

There is some correspondence between this table and Figure 1. The top left hand corner of the table shows that there is heavy use of fuzzy logic in scheduling and design, and KBS are used mainly on design problems. In the bottom right hand corner, neural networks are employed in many applications of process planning, control, quality, maintenance and fault diagnosis.

There are also three notable differences from our personal expectations which we discuss below.

First, there is considerable use of GAs and NNs on design problems. Looking more closely at these applications, a third of these applications are about drug design and involve quantifying structure-activity relationships (e.g., (Kovesdi et al. 1999; Polanski et al. 2002; Polanski et al. 2000; So and Karplus 1997; Terfloth and 
Gasteiger 2001). A further 20\% are applications in Engineering design such as design of concrete structures (Adeli and Park 1995; Cladera and Mari 2004; Deng et al. 2003; Dias and Pooliyadda 2001; Hadi 2003), design of cold-form steel (Adeli and Park 1995; El-Kassas et al. 2001; El-Kassas et al. 2002; Karim and Adeli 1999) and the design of polymers (Zhang and Friedrich 2003). These applications are relatively well defined and therefore explain the use of neural networks and GAs.

A second difference from the expectations suggested in Figure 1 is that, having characterised fuzzy logic as a technology particularly suitable for the executive level and for unstructured problems, their use in process planning and control, an area that we consider to be more operational, may seem surprising. However, many problems in control are relatively well structured in terms of the parameters required, but where the parameters are not precise, hence requiring the use of fuzzy logic. Examples include problems such as controlling an oxygen furnace (Kubat et al. 2004) and combustion control of stoker-fired boilers ( $\mathrm{Li}$ and Chang 2000).

A third difference from our expectations is the relatively low of use of CBR in operations management. As one might expect, CBR is used on design problems such as CAD; however, the use of CBR in the other areas is remarkably low and even in design, there are only a few studied that focus on creative design ( Kolodnerand Wills (1996) is a rare exception). This is despite some early successes in the area of scheduling (Miyashita et al. 1996) . One possible reason for this limited use of CBR might be that most of the focus by the CBR research community has been on the retrieval phases and not as much effort has been on the more challenging adaptation phase making them less flexible and harder to use to solve the other areas.

We now turn our attention to the question: what are the trends? Figure 2 shows the trends for each of the four areas of operations management on a bi-annual basis, from 1995 to 2004.

Both Design and Scheduling has similar trends. The use of GAs is growing substantially and the use of KBS is reducing, perhaps because it is becoming less fashionable and considered to be main stream, rather than research worthy. The underlying problem for both these areas involves optimising an objective function subject to constraints. In the case of scheduling, the objective is typically to minimise tardiness while in design, it is typically to meet user satisfaction on market driven goals. This underlying similarity may explain the similar trends we observe.

Neural networks, particularly the backpropagation algorithm, have been very successful in classification and prediction, and their use for fault diagnosis and quality maintenance continues to grow. Their use in process control and planning peaked in 1990-2000, and has declined somewhat in 2001, but is increasing again. However, neural networks have remained the dominant AI technology for process planning and control throughout the last decade. 

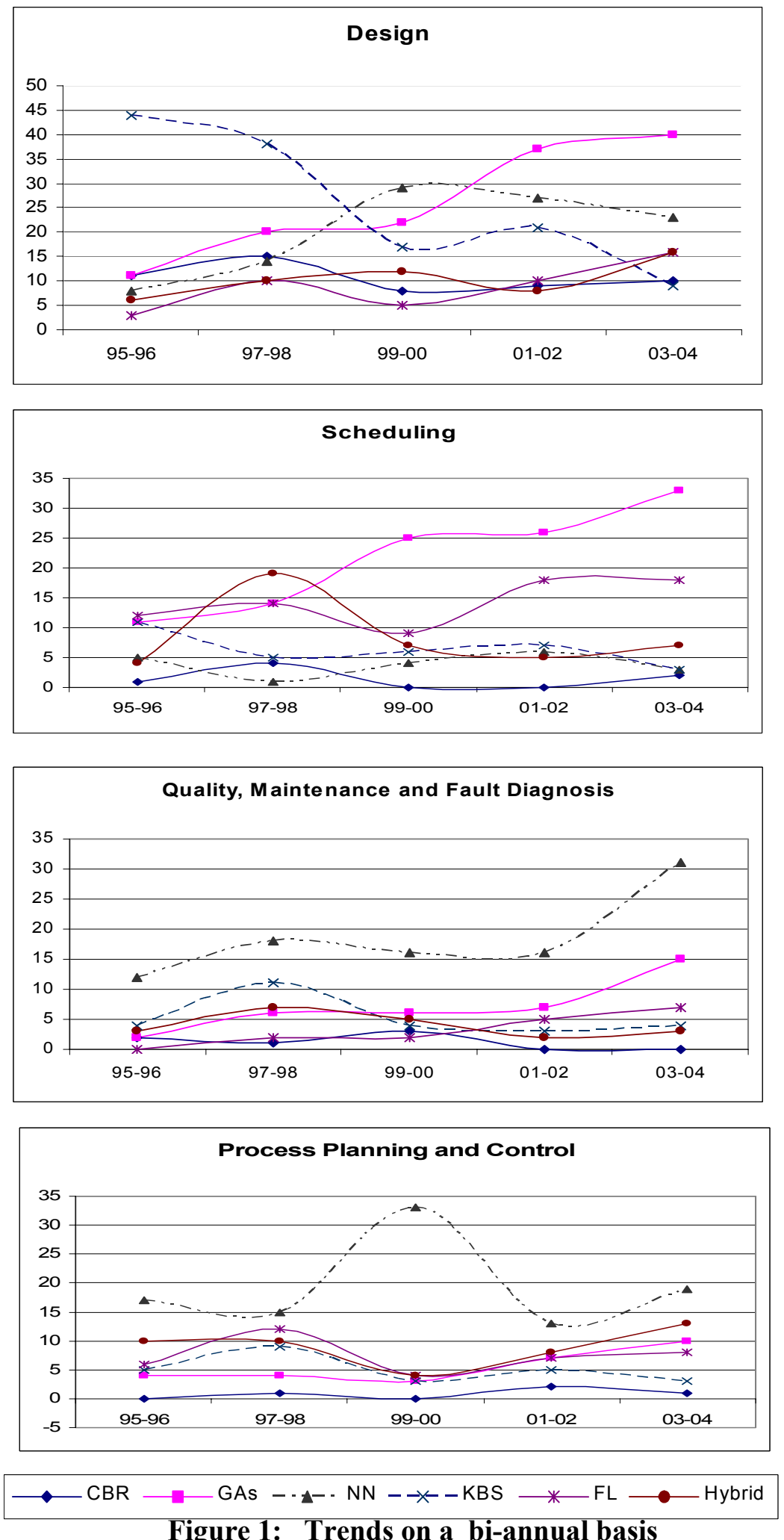

Figure 1: Trends on a bi-annual basis

The last, and most difficult question that we raised is: What should the future direction of research be? 
As mentioned in the introduction, Ackoff's perceptions, even as long ago as the 70's suggested that there was insufficient work on the executive and less defined problems. The trends above seem to confirm that this lack of focus on the more executive decision making problems has continued in the application of AI in Operations Management. This may be due to the nature of the AI techniques but may also be due to external factors, such as pressures on academics to publish, forcing a preference for quantity rather than innovation. Individual AI techniques have shown their power and range of effectiveness, such as the use of GAs in scheduling, but extending the range of problems that can be solved using AI techniques may well require using the combined power of hybrid systems. Although there are some very good examples of the uses of hybrid approaches, such as the use of neuro-fuzzy controllers, the number of publications is surprisingly low and there is no clear increasing trend. Integrating hybrid approaches in a way that takes advantage of the capabilities of different technologies is a non-trivial task and the development of a framework or an agent-based architecture to support a dynamic and cooperative approach to solving problems in operations management seems the natural way forward if the field is to go beyond the kind of problems we know can already be solved.

\section{CONCLUSION}

This paper has surveyed the application of AI techniques in the area of operations management, covering over 1200 papers since 1995. The survey confirms various trends, some that one might expect, and others that are less expected:

- There is heavy use of fuzzy logic in design and scheduling

- Neural networks are dominant in process planning and control.

- Many drug design applications utilise neural networks and GAs

- There is surprisingly low use of case based reasoning other than in design

In terms of trends, there is a decline in publications that describe applications that use KBS, perhaps because it is now less fashionable and research worthy. There is a definite increasing trend in the use of GAs in all areas and most notably in scheduling.

There is no apparent growth in the use of hybrid approaches that take advantage of the strengths of different AI techniques and there appears no further progress in moving towards using AI techniques for problems, such as creative design, that are more challenging. These remain relatively unexplored areas of research that we hope the community will pursue. 


\section{REFERENCES}

Aburto L, Weber R (2005). Improved supply chain management based on hybrid demand forecasts. Applied Soft Computing In Press, Corrected Proof.

Ackoff RL (1979a). The future of operational research is past. Journal of the Operational Research Society 30, 93-104.

Ackoff RL (1979b). Resurrecting the future of Operational Research. Journal of the Operational Research Society 30, 189-199.

Ackoff RL (2001). OR: after the post mortem. Systems dynamics Review 17, 34-40.

Ackoff RL, Sasieni M (1968). 'Foundations of Operations Research.' (John Wiley: New York)

Acosta G, Todorovich E (2003). Genetic algorithms and fuzzy control: a practical synergism for industrial applications. Computers in Industry 52, 183-195.

Acosta GG, Verucchi CJ, Gelso ER (2005). A current monitoring system for diagnosing electrical failures in induction motors. Mechanical Systems and Signal Processing In Press, Corrected Proof.

Adamopoulos GI, Pappis CP (1996). A fuzzy-linguistic approach to a multi-criteria sequencing problem. European Journal of Operational Research 92, 628-636.

Adamopoulos GI, Pappis CP (1998). A Neighbourhood-based Hybrid Method for Scheduling with Fuzzy Due-dates. International Transactions in Operational Research 5, 147-153.

Adeli H, Park HS (1995). Optimization of space structures by neural dynamics. Neural Networks $\mathbf{8}$, 769-781.

Aguilar JL, Leiss ELEL (2004). Data dependent loop scheduling based on genetic algorithms for distributed and shared memory systems. Journal of Parallel and Distributed Computing 64, 578-590.

Aguilera PA, Frenich AG, Torres JA, Castro H, Vidal JLM, Canton M (2001). Application of the kohonen neural network in coastal water management: methodological development for the assessment and prediction of water quality. Water Research 35, 4053-4062.

Ahmad I, Dhodhi MK (1996). Multiprocessor scheduling in a genetic paradigm. Parallel Computing 22, 395-406.

Aickelin U, Dowsland KA (2004). An indirect Genetic Algorithm for a nurse-scheduling problem. Computers \& Operations Research 31, 761-778.

Al-Assaf Y (2004). Recognition of control chart patterns using multi-resolution wavelets analysis and neural networks*. Computers \& Industrial Engineering 47, 17-29.

Al-Najjar B, Alsyouf I (2003). Selecting the most efficient maintenance approach using fuzzy multiple criteria decision making. International Journal of Production Economics 84, 85-100.

Amen R, Vomacka P (2001). Case-based reasoning as a tool for materials selection. Materials \& Design 22, 353-358.

Arezoo B, Ridgway K, Al-Ahmari AMA (2000). Selection of cutting tools and conditions of machining operations using an expert system. Computers in Industry 42, 43-58.

Avramenko Y, Nystrom L, Kraslawski A (2004). Selection of internals for reactive distillation column-case-based reasoning approach. Computers \& Chemical Engineering 28, 37-44. 
Azlan Hussain M (1999). Review of the applications of neural networks in chemical process control -simulation and online implementation. Artificial Intelligence in Engineering 13, 55-68.

Baita F, Pesenti R, Ukovich W, Favaretto D (2000). A comparison of different solution approaches to the vehicle scheduling problem in a practical case. Computers \& Operations Research 27, 1249-1269.

Baker BM (1999). A spreadsheet modelling approach to the assortment problem. European Journal of Operational Research 114, 83-92.

Bansal D, Evans DJ, Jones B (2004). A real-time predictive maintenance system for machine systems. International Journal of Machine Tools and Manufacture 44, 759-766.

Baroni P, Canzi U, Guida G (1997). Fault diagnosis through history reconstruction: An application to power transmission networks. Expert Systems with Applications 12, 37-52.

Batanov DN, Cheng Z (1995). An object-oriented expert system for fault diagnosis in the ethylene distillation process. Computers in Industry 27, 237-249.

Bayraktar D (1998). A knowledge-based expert system approach for the auditing process of some elements in the quality assurance system. International Journal of Production Economics 56-57, 37-46.

Beaulah SA, Chalabi ZS (1997). Intelligent real-time fault diagnosis of greenhouse sensors. Control Engineering Practice 5, 1573-1580.

Ben-Nakhi AE, Mahmoud MA (2002). Energy conservation in buildings through efficient A/C control using neural networks. Applied Energy 73, 5-23.

Bhaskara Reddy SV, Shunmugam MS, Narendran TT (1998). Optimal sub-division of the depth of cut to achieve minimum production cost in multi-pass turning using a genetic algorithm. Journal of Materials Processing Technology 79, 101-108.

Blackard JA, Dean DJ (1999). Comparative accuracies of artificial neural networks and discriminant analysis in predicting forest cover types from cartographic variables. Computers and Electronics in Agriculture 24, 131-151.

Bogataj M, Usenik J (2005). Fuzzy approach to the spatial games in the total market area. International Journal of Production Economics 93-94, 493-503.

Booth C, McDonald JR (1998). The use of artificial neural networks for condition monitoring of electrical power transformers. Neurocomputing 23, 97-109.

Braun TD, et al. (2001). A Comparison of Eleven Static Heuristics for Mapping a Class of Independent Tasks onto Heterogeneous Distributed Computing Systems. Journal of Parallel and Distributed Computing 61, 810-837.

Cai H, He W, Zhang D (2003). A semantic style driving method for products' appearance design. Journal of Materials Processing Technology 139, 233-236.

Cai X, Li KN (2000). A genetic algorithm for scheduling staff of mixed skills under multi-criteria. European Journal of Operational Research 125, 359-369.

Cai YD, Yu H, Chou KC (1998). Artificial neural network method for predicting HIV protease cleavage sites in protein. Journal Of Protein Chemistry 17, 607-615.

Cantoni M, Marseguerra M, Zio E (2000). Genetic algorithms and Monte Carlo simulation for optimal plant design. Reliability Engineering \& System Safety 68, 29-38.

Cappellini V, Emiliani P, Mecocci A, Montalto A (1995). An expert system for digital filter design. Signal Processing 46, 159-168. 
Caraffa V, Ianes S, P. Bagchi T, Sriskandarajah C (2001). Minimizing makespan in a blocking flowshop using genetic algorithms. International Journal of Production Economics 70, 101-115.

Cardon A, Galinho T, Vacher J-P (2000). Genetic algorithms using multi-objectives in a multi-agent system. Robotics and Autonomous Systems 33, 179-190.

Carvalho MT, Durao F (2002). Control of a flotation column using fuzzy logic inference. Fuzzy Sets and Systems 125, 121-133.

Cavory G, Dupas R, Goncalves G (2001). A genetic approach to the scheduling of preventive maintenance tasks on a single product manufacturing production line. International Journal of Production Economics 74, 135-146.

Celano G., Fichera S. (1999). Multiobjective economic design of an X control chart. Computers \& Industrial Engineering 37, 129-132.

Chambers M, Mount-Campbell CA (2002). Process optimization via neural network metamodeling. International Journal of Production Economics 79, 93-100.

Chan CK, Cheung BK-S, Langevin A (2003). Solving the multi-buyer joint replenishment problem with a modified genetic algorithm. Transportation Research Part B: Methodological 37, 291-299.

Chanas S, Kasperski A (2001). Minimizing maximum lateness in a single machine scheduling problem with fuzzy processing times and fuzzy due dates. Engineering Applications of Artificial Intelligence 14, 377-386.

Chanas S, Kasperski A (2003). On two single machine scheduling problems with fuzzy processing times and fuzzy due dates. European Journal of Operational Research 147, 281-296.

Chang H-C, Dong L, Liu FX, Lu WF (2000). Indexing and retrieval in machining process planning using case-based reasoning. Artificial Intelligence in Engineering 14, 1-13.

Chau KW, Albermani F (2003). A coupled knowledge-based expert system for design of liquidretaining structures. Automation in Construction 12, 589-602.

Chen WC, Chang N-B, Chen J-C (2003). Rough set-based hybrid fuzzy-neural controller design for industrial wastewater treatment. Water Research 37, 95-107.

Chen X, Li YS, Liu Z, Yin K, Li Z, Wai OW, King B (2004). Integration of multi-source data for water quality classification in the Pearl River estuary and its adjacent coastal waters of Hong Kong. Continental Shelf Research 24, 1827-1843.

Cheung CF, Lee WB, Wang WM, Chu KF, To S (2003). A multi-perspective knowledge-based system for customer service management. Expert Systems with Applications 24, 457-470.

Chin K-S, Pun K-F, Lau H (2003). Development of a knowledge-based self-assessment system for measuring organisational performance. Expert Systems with Applications 24, 443-455.

Choy KL, Lee WB, Lo V (2002). An intelligent supplier management tool for benchmarking suppliers in outsource manufacturing. Expert Systems with Applications 22, 213-224.

Choy KL, Lee WB, Lo V (2003). Design of an intelligent supplier relationship management system: a hybrid case based neural network approach. Expert Systems with Applications 24, 225-237.

Cladera A, Mari AR (2004). Shear design procedure for reinforced normal and high-strength concrete beams using artificial neural networks. Part II: beams with stirrups. Engineering Structures 26, $927-$ 936. 
Cox IJ, Lewis RW, Ransing RS, Laszczewski H, Berni G (2002). Application of neural computing in basic oxygen steelmaking. Journal of Materials Processing Technology 120, 310-315.

Cunningham P, Smyth B, Bonzano A (1998). An incremental retrieval mechanism for case-based electronic fault diagnosis. Knowledge-Based Systems 11, 239-248.

Dagli CH, Sittisathanchai S (1995). Genetic neuro-scheduler: A new approach for job shop scheduling. International Journal of Production Economics 41, 135-145.

Dash S, Rengaswamy R, Venkatasubramanian V (2003). Fuzzy-logic based trend classification for fault diagnosis of chemical processes. Computers \& Chemical Engineering 27, 347-362.

Davenport JC, Hammond P, de Mattos MG (1996). The acquisition and validation of removable partial denture design knowledge. II. Design rules and expert reaction. Journal Of Oral Rehabilitation 23, 811-824.

de Brito J, Branco FA, Thoft-Christensen P, Sorensen JD (1997). An expert system for concrete bridge management. Engineering Structures 19, 519-526.

de Silva CW, Wickramarachchi N (1998). Knowledge-based supervisory control system of a fish processing workcell; Part I: system development. Engineering Applications of Artificial Intelligence 11, 97-118.

Deng J, Yue ZQ, Tham LG, Zhu HH (2003). Pillar design by combining finite element methods, neural networks and reliability: a case study of the Feng Huangshan copper mine, China. International Journal of Rock Mechanics and Mining Sciences 40, 585-599.

Di L, Srikanthan T, Chandel RS, Katsunori I (2001). Neural-network-based self-organized fuzzy logic control for arc welding. Engineering Applications of Artificial Intelligence 14, 115-124.

Dias WPS, Pooliyadda SP (2001). Neural networks for predicting properties of concretes with admixtures. Construction and Building Materials 15, 371-379.

Dillon JD, O'Malley MJ (2002). A Lagrangian augmented Hopfield network for mixed integer nonlinear programming problems. Neurocomputing 42, 323-330.

Ding L, Yue Y (2004). Novel ANN-based feature recognition incorporating design by features. Computers in Industry 55, 197-222.

Drstvensek I, Ficko M, Pahole I, Balic J (2004). A model of simulation environment for prediction and optimisation of production processes. Journal of Materials Processing Technology 155-156, 1641 1646.

Du TC-T, Wolfe PM (1997). Implementation of fuzzy logic systems and neural networks in industry. Computers in Industry 32, 261-272.

Dzeng R-J, Tommelein ID (2004). Product modeling to support case-based construction planning and scheduling. Automation in Construction 13, 341-360.

Easton FF, Mansour N (1999). A distributed genetic algorithm for deterministic and stochastic labor scheduling problems. European Journal of Operational Research 118, 505-523.

Eldin NN, Senouci AB (1995). Use of neural networks for condition rating of jointed concrete pavements. Advances in Engineering Software 23, 133-141.

El-Gamal MA, Abdulghafour M (2003). Fault isolation in analog circuits using a fuzzy inference system. Computers \& Electrical Engineering 29, 213-229.

El-Kassas EMA, Mackie RI, El-Sheikh AI (2001). Using neural networks in cold-formed steel design. Computers \& Structures 79, 1687-1696. 
El-Kassas EMA, Mackie RI, El-Sheikh AI (2002). Using neural networks to predict the design load of cold-formed steel compression members. Advances in Engineering Software 33, 713-719.

Estaben M, Polit M, Steyer JP (1997). Fuzzy control for an anaerobic digester. Control Engineering Practice 5, 1303-1310.

Eykhoff P (1974). 'System Identification - Parameter and State Estimation.' (John Wiley: New York)

Faltings B, Sun K (1996). : supporting innovative mechanism shape design. Computer-Aided Design 28, 207-216.

Feigenbaum E (1977). The art of artificial intelligence: Themes and case studies in knowledge engineering. In 'Proceedings of the Fifth International Joint Conference on Artificial Intelligence (IJCAI)'. Cambridge, MA pp. 1014-1029. (William Kaufmann)

Feigenbaum E, Shrobe H (1993). The Japanese national Fifth Generation project: Introduction, survey, and evaluation. Future Generation Computer Systems 9, 105-117.

Feng C-XJ, Li P-G, Liang M (2001). Fuzzy mapping of requirements onto functions in detail design. Computer-Aided Design 33, 425-437.

Fonseca DJ, Navaresse D (2002). Artificial neural networks for job shop simulation. Advanced Engineering Informatics 16, 241-246.

Foo SY, Takefuji Y, Szu H (1995). Scaling properties of neural networks for job-shop scheduling. Neurocomputing 8, 79-91.

Foong David Law Y, Bun Foong S, Eng Jeremiah Kwan S (1997). An integrated case-based reasoning approach for intelligent help desk fault management. Expert Systems with Applications 13, 265-274.

Fordyce K, Norden P, Sullivan G (1987). Artificial intelligence and the Management Science Practitioner: links between Operations Research and Expert Systems. Interfaces 17, 34-40.

Frank PM, Koppen-Seliger B (1997a). Fuzzy logic and neural network applications to fault diagnosis. International Journal of Approximate Reasoning 16, 67-88.

Frank PM, Koppen-Seliger B (1997b). New developments using AI in fault diagnosis. Engineering Applications of Artificial Intelligence 10, 3-14.

Furuta H, Hase H, Watanabe E, Tonegawa T, Morimoto H (1996). Applications of genetic algorithm to aesthetic design of dam structures. Advances in Engineering Software 25, 185-195.

Garcia E, Guyennet H, Lapayre JC, Zerhouni N (2004). A new industrial cooperative tele-maintenance platform. Computers \& Industrial Engineering 46, 851-864.

Geng G, Li LX (2001). Scheduling railway freight cars. Knowledge-Based Systems 14, 289-297.

Gonzalez-Uriel A, Roanes-Lozano E (2004). A knowledge-based system for house layout selection. Mathematics and Computers in Simulation 66, 43-54.

Graham IJ, Case K, Wood RL (2001). Genetic algorithms in computer-aided design. Journal of Materials Processing Technology 117, 216-221.

Guh R-S, Tannock JDT, O'Brien C (1999). IntelliSPC: a hybrid intelligent tool for on-line economical statistical process control. Expert Systems with Applications 17, 195-212.

Guillaume S, Charnomordic B (2001). Knowledge discovery for control purposes in food industry databases. Fuzzy Sets and Systems 122, 487-497. 
Guyot O, Monredon T, LaRosa D, Broussaud A (2004). VisioRock, an integrated vision technology for advanced control of comminution circuits. Minerals Engineering 17, 1227-1235.

Hadi MNS (2003). Neural networks applications in concrete structures. Computers \& Structures 81, 373-381.

Hanson L, Wienholt W, Sperling L (2003). A control handling comfort model based on fuzzy logics. International Journal of Industrial Ergonomics 31, 87-100.

Hapke M, Slowinski R (1996). Fuzzy priority heuristics for project scheduling. Fuzzy Sets and Systems 83, 291-299.

Hasenauer H, Merkl D, Weingartner M (2001). Estimating tree mortality of Norway spruce stands with neural networks. Advances in Environmental Research 5, 405-414.

Heindl B, Schmidt R, Schmid G, Haller M, Pfaller P, Gierl L, Pollwein B (1997). A case-based consiliarius for therapy recommendation (ICONS): computer-based advice for calculated antibiotic therapy in intensive care medicine. Computer Methods And Programs In Biomedicine 52, 117-127.

Ho WK, Lee TH, Tay EB (1998). Knowledge-based multivariable PID control. Control Engineering Practice 6, 855-864.

Hong Y-S, Rosen MR (2001). Intelligent characterisation and diagnosis of the groundwater quality in an urban fractured-rock aquifer using an artificial neural network. Urban Water 3, 193-204.

Hou T, Xu X (2001). A new molecular simulation software package - Peking University Drug Design System (PKUDDS) for structure-based drug design. Journal of Molecular Graphics and Modelling 19, $455-465$.

Hrncirik P, Nahlik J, Vovsik J (2002). The BIOGENES system for knowledge-based bioprocess control. Expert Systems with Applications 23, 145-153.

Hsiao S-W, Huang HC (2002). A neural network based approach for product form design. Design Studies 23, 67-84.

Hsieh K-H, Tien F-C (2004). Self-organizing feature maps for solving location-allocation problems with rectilinear distances. Computers \& Operations Research 31, 1017-1031.

Hu ZY, Huang GH, Chan CW (2003). A fuzzy process controller for in situ groundwater bioremediation. Engineering Applications of Artificial Intelligence 16, 131-147.

Huang K, Chen F-Q, Lu D-W (2001). Artificial neural network-aided design of a multi-component catalyst for methane oxidative coupling. Applied Catalysis A: General 219, 61-68.

Huang K, Zhan X-L, Chen F-Q, Lu D-W (2003). Catalyst design for methane oxidative coupling by using artificial neural network and hybrid genetic algorithm. Chemical Engineering Science 58, 81-87.

Huang S-J (1998). Hydroelectric generation scheduling--an application of genetic-embedded fuzzy system approach. Electric Power Systems Research 48, 65-72.

Humphreys P, McIvor R, Chan F (2003). Using case-based reasoning to evaluate supplier environmental management performance. Expert Systems with Applications 25, 141-153.

Hwang H, Choi B, Lee M-J (2005). A model for shelf space allocation and inventory control considering location and inventory level effects on demand. International Journal of Production Economics 97, 185-195.

Ibricacute, et al. (2003). Artificial neural networks in the modeling and optimization of aspirin extended release tablets with Eudragit L 100 as matrix substance. AAPS PharmSciTech [Electronic Resource] 4, E9. 
Ishii H, Tada M (1995). Single machine scheduling problem with fuzzy precedence relation. European Journal of Operational Research 87, 284-288.

Ishikawa T, Terano T (1996). Analogy by abstraction: Case retrieval and adaptation for inventive design expert systems. Expert Systems with Applications 10, 351-356.

Iyer SK, Saxena B (2004). Improved genetic algorithm for the permutation flowshop scheduling problem. Computers \& Operations Research 31, 593-606.

Janabi-Sharifi F (2005). A neuro-fuzzy system for looper tension control in rolling mills. Control Engineering Practice 13, 1-13.

Jeffries M, Lai E, Hull JB (2003). A new approach to process control for a bottling plant. Journal of Materials Processing Technology 133, 122-127.

Jeffries M, Lai E, Plantenberg DH, Hull JB (2001). A fuzzy approach to the condition monitoring of a packaging plant. Journal of Materials Processing Technology 109, 83-89.

Jiang B, Lau H, Chan FTS, Jiang H (1999). An automatic process planning system for the quick generation of manufacturing process plans directly from CAD drawings. Journal of Materials Processing Technology 87, 97-106.

Jo JH, Gero JS (1998). Space layout planning using an evolutionary approach. Artificial Intelligence in Engineering 12, 149-162.

Joo Mo K, Seok Oh Y, Sup Yoon E, Wook Jeong C (1997). Development of operation-aided system for chemical processes. Expert Systems with Applications 12, 455-464.

Jota PRS, Islam SM, Wu T, Ledwich G (1998). A class of hybrid intelligent system for fault diagnosis in electric power systems. Neurocomputing 23, 207-224.

Kameshki ES, Saka MP (2001). Genetic algorithm based optimum bracing design of non-swaying tall plane frames. Journal of Constructional Steel Research 57, 1081-1097.

Kameshki ES, Saka MP (2003). Genetic algorithm based optimum design of nonlinear planar steel frames with various semi-rigid connections. Journal of Constructional Steel Research 59, 109-134.

Kapanoglu M, Miller WA (2004). An evolutionary algorithm-based decision support system for managing flexible manufacturing. Robotics and Computer-Integrated Manufacturing 20, 529-539.

Karim A, Adeli H (1999). Global optimum design of cold-formed steel hat-shape beams. Thin-Walled Structures 35, 275-288.

Karr CL (1996). Adaptive process control using biological paradigms. Journal of Network and Computer Applications 19, 21-44.

Karr CL (2003). Control of a phosphate processing plant via a synergistic architecture for adaptive, intelligent control. Engineering Applications of Artificial Intelligence 16, 21-30.

Karr CL, Freeman LM (1997). Genetic-algorithm-based fuzzy control of spacecraft autonomous rendezvous. Engineering Applications of Artificial Intelligence 10, 293-300.

Karr CL, Yeager D (1995). Calibrating computer models of mineral processing equipment using genetic algorithms. Minerals Engineering 8, 989-998.

Karras DA, Zorkadis V (2003). On neural network techniques in the secure management of communication systems through improving and quality assessing pseudorandom stream generators. Neural Networks 16, 899-905. 
Karsak EE (2004). Fuzzy multiple objective programming framework to prioritize design requirements in quality function deployment. Computers \& Industrial Engineering 47, 149-163.

Kenig S, Ben-David A, Omer M, Sadeh A (2001). Control of properties in injection molding by neural networks. Engineering Applications of Artificial Intelligence 14, 819-823.

Khouja M, Michalewicz Z, Wilmot M (1998). The use of genetic algorithms to solve the economic lot size scheduling problem. European Journal of Operational Research 110, 509-524.

Kim H-S, Cho S-B (2000). Application of interactive genetic algorithm to fashion design. Engineering Applications of Artificial Intelligence 13, 635-644.

Kim KW, Gen M, Yamazaki G (2003). Hybrid genetic algorithm with fuzzy logic for resourceconstrained project scheduling. Applied Soft Computing 2, 174-188.

King JMP, Banares-Alcantara R, Manan ZA (1999). Minimising environmental impact using CBR: an azeotropic distillation case study. Environmental Modelling and Software 14, 359-366.

Knosala R, Wal T (2001). A production scheduling problem using genetic algorithm. Journal of Materials Processing Technology 109, 90-95.

Kobbacy KAH (1981). Power Consumption and Gas Dispersion in Agitated Vessels, PhD Thesis. Univeristy of Bath, UK.

Kolodner JL, Wills LM (1996). Powers of observation in creative design. Design Studies 17, 385-416.

Kovesdi I, Dominguez-Rodriguez MF, Orfi L, Naray-Szabo G, Varro A, Papp JG, Matyus P (1999). Application of neural networks in structure-activity relationships. Medicinal Research Reviews 19, 249-269.

Kubat C, Taskin H, Artir R, Yilmaz A (2004). Bofy-fuzzy logic control for the basic oxygen furnace (BOF). Robotics and Autonomous Systems 49, 193-205.

Kulkarni AJ, Krishnamurthy K, Deshmukh SP, Mishra RS (2004). Microstructural optimization of alloys using a genetic algorithm. Materials Science and Engineering A 372, 213-220.

Kuo RJ (2000). Multi-sensor integration for on-line tool wear estimation through artificial neural networks and fuzzy neural network. Engineering Applications of Artificial Intelligence 13, 249-261.

Kuo RJ, Cohen PH (1998). Manufacturing process control through integration of neural networks and fuzzy model. Fuzzy Sets and Systems 98, 15-31.

Kurz ME, Askin RG (2004). Scheduling flexible flow lines with sequence-dependent setup times. European Journal of Operational Research 159, 66-82.

Lam SS, Cai X (2002). Single machine scheduling with nonlinear lateness cost functions and fuzzy due dates. Nonlinear Analysis: Real World Applications 3, 307-316.

Lapa CMF, Pereira CMNA, Mol ACdA (2000). Maximization of a nuclear system availability through maintenance scheduling optimization using a genetic algorithm. Nuclear Engineering and Design 196, 219-231.

Laring J, Falk K-J, Kadefors R, Ortengren R (1996). Computer aided workplace design: An approach to create a tool for the production engineer. International Journal of Industrial Ergonomics 17, 323330 .

Lee Dongkon, Lee Kyung-Ho (1999). An approach to case-based system for conceptual ship design assistant. Expert Systems with Applications 16, 97-104. 
Lee HC, Dagli CH (1997). A parallel genetic-neuro scheduler for job-shop scheduling problems. International Journal of Production Economics 51, 115-122.

Lee KH, Lee JK, Park NS (1998). Intelligent approach to a CAD system for the layout design of a ship engine room. Computers \& Industrial Engineering 34, 599-608.

Lee MR, Wong WY, Zhang DM (1999). A knowledge-based framework for clinical incident management. Expert Systems with Applications 17, 315-325.

Lee PG (2000). Process control and artificial intelligence software for aquaculture. Aquacultural Engineering 23, 13-36.

Lee YH, Jeong CS, Moon C (2002). Advanced planning and scheduling with outsourcing in manufacturing supply chain. Computers \& Industrial Engineering 43, 351-374.

Lei Y, Peng Y, Ruan X (2001). Applying case-based reasoning to cold forging process planning. Journal of Materials Processing Technology 112, 12-16.

Lennox B, Montague GA, Frith AM, Gent C, Bevan V (2001). Industrial application of neural networks -- an investigation. Journal of Process Control 11, 497-507.

Leps M, Sejnoha M (2003). New approach to optimization of reinforced concrete beams. Computers \& Structures 81, 1957-1966.

Leung D, Romagnoli J (2002). An integration mechanism for multivariate knowledge-based fault diagnosis. Journal of Process Control 12, 15-26.

Li W, Chang X (2000). Application of hybrid fuzzy logic proportional plus conventional integralderivative controller to combustion control of stoker-fired boilers. Fuzzy Sets and Systems 111, $267-$ 284.

Liang M, Yeap T, Hermansyah A, Rahmati S (2003). Fuzzy control of spindle torque for industrial CNC machining. International Journal of Machine Tools and Manufacture 43, 1497-1508.

Liang W-Y, Huang C-C (2005). Agent-based demand forecast in multi-echelon supply chain. Decision Support Systems In Press, Corrected Proof.

Li-Chiun Wei, Chang R-S (1997). Broadcast scheduling in packet radio networks by Hopfield neural networks. Information Processing Letters 63, 271-276.

Lieckens K, Vandaele N (2005). Reverse logistics network design with stochastic lead times. Computers \& Operations Research In Press, Corrected Proof.

Lighthill J (1973). 'The Lighthill Report.' UK Science and Engineering Research Council, London, UK.

Lin C-T, Chiu H, Chu P-Y (2005). Agility index in the supply chain. International Journal of Production Economics In Press, Corrected Proof.

Ling FYYFYY, Liu M (2004). Using neural network to predict performance of design-build projects in Singapore. Building and Environment 39, 1263-1274.

Linkens DA, Abbod MF, Browne A, Cade N (2000). Intelligent control of a cryogenic cooling plant based on blackboard system architecture. ISA Transactions 39, 327-343.

Liu Y, Liu Y, Liu D, Cao T, Han S, Xu G (2001). Design of CO2 hydrogenation catalyst by an artificial neural network. Computers \& Chemical Engineering 25, 1711-1714.

Lopes JA, Menezes JC (2004). Multivariate monitoring of fermentation processes with non-linear modelling methods. Analytica Chimica Acta 515, 101-108. 
Luxhoj JT (1998). An artificial neural network for nonlinear estimation of the turbine flow-meter coefficient. Engineering Applications of Artificial Intelligence 11, 723-734.

Luxhoj JT, Williams TP (1996). Integrated decision support for aviation safety inspectors. Finite Elements in Analysis and Design 23, 381-403.

Mak KL, Wong YS, Huang GQ (1999). Optimal inventory control of lumpy demand items using genetic algorithms. Computers \& Industrial Engineering 37, 273-276.

Malmborg CJ (1996). A genetic algorithm for service level based vehicle scheduling. European Journal of Operational Research 93, 121-134.

Martorell S, Sanchez A, Carlos S, Serradell V (2004). Alternatives and challenges in optimizing industrial safety using genetic algorithms. Reliability Engineering \& System Safety 86, 25-38.

Matsuzaki K, Irohara T, Yoshimoto K (1999). Heuristic algorithm to solve the multi-floor layout problem with the consideration of elevator utilization. Computers \& Industrial Engineering 36, 487 502.

Mattfeld DC, Bierwirth C (2004). An efficient genetic algorithm for job shop scheduling with tardiness objectives. European Journal of Operational Research 155, 616-630.

Mechefske CK (1998). OBJECTIVE MACHINERY FAULT DIAGNOSIS USING FUZZY LOGIC. Mechanical Systems and Signal Processing 12, 855-862.

Mejasson P, Petridis M, Knight B, Soper A, Norman P (2001). Intelligent design assistant (IDA): a case base reasoning system for material and design. Materials \& Design 22, 163-170.

Mendes JRP, Morooka CK, Guilherme IR (2003). Case-based reasoning in offshore well design. Journal of Petroleum Science and Engineering 40, 47-60.

Meziane F, Vadera S, Kobbacy KAH, Proudlove N (2000). Intelligent Systems in Manufacturing: Current Developments and Future Prospects. The International Journal of Manufacturing Technology Management 11, 218-238.

Mihailidis A, Fernie GR, Barbenel JC (2001). The use of artificial intelligence in the design of an intelligent cognitive orthosis for people with dementia. Assistive Technology: The Official Journal Of RESNA 13, 23-39.

Milne R, Nicol C, Trave-Massuyes L (2001). with model based diagnosis: initial deployment. Knowledge-Based Systems 14, 213-222.

Ming XG, Mak KL (2001). Intelligent approaches to tolerance allocation and manufacturing operations selection in process planning. Journal of Materials Processing Technology 117, 75-83.

Miyamoto A, Kawamura K, Nakamura H (2001). Development of a bridge management system for existing bridges. Advances in Engineering Software 32, 821-833.

Miyashita K, Sycara K, Mizoguchi R (1996). Modeling ill-structured optimization tasks through cases. Decision Support Systems 17, 345-364.

Mohamed A, Celik T (2002). Knowledge based-system for alternative design, cost estimating and scheduling. Knowledge-Based Systems 15, 177-188.

Moisen GG, Frescino TS (2002). Comparing five modelling techniques for predicting forest characteristics. Ecological Modelling 157, 209-225.

Molero J, Sanchez-Cabeza JA, Merino J, Mitchell PI, Vidal-Quadras A (1999). Impact of 134Cs and 137Cs from the Chernobyl reactor accident on the Spanish Mediterranean marine environment. Journal of Environmental Radioactivity 43, 357-370. 
Monostori L, Viharos ZJ, Markos S (2000). Satisfying various requirements in different levels and stages of machining using one general ANN-based process model. Journal of Materials Processing Technology 107, 228-235.

Moore CJ, Miles JC, Rees DWG (1997). Decision support for conceptual bridge design. Artificial Intelligence in Engineering 11, 259-272.

Moore CT, Conroy MJ, Boston K (2000). Forest management decisions for wildlife objectives: system resolution and optimality. Computers and Electronics in Agriculture 27, 25-39.

Morimoto T, De Baerdemaeker J, Hashimoto Y (1997). An intelligent approach for optimal control of fruit-storage process using neural networks and genetic algorithms. Computers and Electronics in Agriculture 18, 205-224.

Motta E, Stutt A, Zdrahal Z, O\&rsquo;Hara K, Shadbolt N (1996). Solving VT in VITAL: a study in model construction and knowledge reuse. International Journal of Human-Computer Studies 44, 333 371.

Muthusamy K, Chin Sung S, Vlach M, Ishii H (2003). Scheduling with fuzzy delays and fuzzy precedences. Fuzzy Sets and Systems 134, 387-395.

Nam DS, Jeong CW, Choe YJ, Yoon ES (1996). Operation-aided system for fault diagnosis of continuous and semi-continuous processes. Computers \& Chemical Engineering 20, 793-803.

Nearchou ACAC (2004). The effect of various operators on the genetic search for large scheduling problems. International Journal of Production Economics 88, 191-203.

$\mathrm{Ng} \mathrm{CW}$, Hussain MA (2004). Hybrid neural network--prior knowledge model in temperature control of a semi-batch polymerization process. Chemical Engineering and Processing 43, 559-570.

Nute D, et al. (2004). NED-2: an agent-based decision support system for forest ecosystem management. Environmental Modelling \& Software 19, 831-843.

Oakley B, Owen K (2000). 'Alvey: Britain's Strategic Computing Initiative.' (MIT Press)

Odetunji OA, Kehinde OO (2005). Computer simulation of fuzzy control system for gari fermentation plant. Journal of Food Engineering 68, 197-207.

Oh J, Wu C (2004). Genetic-algorithm-based real-time task scheduling with multiple goals. Journal of Systems and Software 71, 245-258.

Omerdic E, Roberts G (2004). Thruster fault diagnosis and accommodation for open-frame underwater vehicles. Control Engineering Practice 12, 1575-1598.

Ortega G, Giron-Sierra JM (1998). Geno-fuzzy control in autonomous servicing of a space station. Engineering Applications of Artificial Intelligence 11, 383-400.

Osman HM, Georgy ME, Ibrahim ME (2003). A hybrid CAD-based construction site layout planning system using genetic algorithms. Automation in Construction 12, 749-764.

Ozyurt B, Sunol AK, Camurdan MC, Mogili P, Hall LO (1998). Chemical plant fault diagnosis through a hybrid symbolic-connectionist machine learning approach. Computers \& Chemical Engineering 22, 299-321.

Paek Y-K, Seo J, Kim G-C (1996). An expert system with case-based reasoning for database schema design. Decision Support Systems 18, 83-95.

Park J, Han SH (2004). A fuzzy rule-based approach to modeling affective user satisfaction towards office chair design. International Journal of Industrial Ergonomics 34, 31-47. 
Park M-K, Lee I, Shon K-M (1998). Using case based reasoning for problem solving in a complex production process. Expert Systems with Applications 15, 69-75.

Park S, Yang X, Saven JG (2004). Advances in computational protein design. Current Opinion in Structural Biology 14, 487-494.

Park Y, Kim S, Lee Y-H (2000). Scheduling jobs on parallel machines applying neural network and heuristic rules. Computers \& Industrial Engineering 38, 189-202.

Partovi FY, Anandarajan M (2002). Classifying inventory using an artificial neural network approach. Computers \& Industrial Engineering 41, 389-404.

Patel SA, Kamrani AK, Orady E (1995). A knowledge-based system for fault diagnosis and maintenance of advanced automated systems. Computers \& Industrial Engineering 29, 147-151.

Peng J, Liu B (2004). Parallel machine scheduling models with fuzzy processing times. Information Sciences 166, 49-66.

Pereira CMNA, Lapa CMF (2003). Parallel island genetic algorithm applied to a nuclear power plant auxiliary feedwater system surveillance tests policy optimization. Annals of Nuclear Energy 30, 16651675 .

Perrot N, Agioux L, Ioannou I, Mauris G, Corrieu G, Trystram G (2004). Decision support system design using the operator skill to control cheese ripening--application of the fuzzy symbolic approach. Journal of Food Engineering 64, 321-333.

Polanski J, Gieleciak R, Bak A, Jarzembek K, Wyszomirski M (2002). A comparative molecular surface analysis (COMSA). A new efficient technique for drug design. Acta Poloniae Pharmaceutica 59, 459-461.

Polanski J, Walczak B, Gieleciak R, Lukaszyk S (2000). Self-organizing neural networks for modeling 3D QSAR--a comparative study. Acta Poloniae Pharmaceutica 57, 76-79.

Praehofer H, Kerschbaummayr J (1999). Case-based reasoning techniques to support reusability in a requirement engineering and system design tool. Engineering Applications of Artificial Intelligence 12, 717-731.

Proudlove N, Vadera S, Kobbacy KAH (1998). The use of intelligent systems in support of the management of operations: an overview,. Special issue of the Journal of Operational Research on Intelligent Systems in Operations Management 49, 682-699.

Rafiq MY, Southcombe C (1998). Genetic algorithms in optimal design and detailing of reinforced concrete biaxial columns supported by a declarative approach for capacity checking. Computers $\&$ Structures 69, 443-457.

Rao M, Wang Q, Cha J (1993). 'Integrated Distributed Intelligent Systems in Manufacturing.' (Chapman \& Hall)

Reynolds KM, Jensen M, Andreasen J, Goodman I (2000). Knowledge-based assessment of watershed condition. Computers and Electronics in Agriculture 27, 315-334.

Rothenfluh TE, Gennari JH, Eriksson H, Puerta AR, Tu SW, Musen MA (1996). Reusable ontologies, knowledge-acquisition tools, and performance systems: PROTEGE-II solutions to Sisyphus-2.

International Journal of Human-Computer Studies 44, 303-332.

Ruiz D, Canton J, Maria Nougues J, Espuna A, Puigjaner L (2001a). On-line fault diagnosis system support for reactive scheduling in multipurpose batch chemical plants. Computers \& Chemical Engineering 25, 829-837. 
Ruiz D, Nougues JM, Puigjaner L (2001b). Fault diagnosis support system for complex chemical plants. Computers \& Chemical Engineering 25, 151-160.

Rywotycki R (2003). Food frying process control system. Journal of Food Engineering 59, 339-342.

Sakawa M, Kubota R (2000). Fuzzy programming for multiobjective job shop scheduling with fuzzy processing time and fuzzy duedate through genetic algorithms. European Journal of Operational Research 120, 393-407.

Samanta B, Al-Araimi SA (2001). An inventory control model using fuzzy logic. International Journal of Production Economics 73, 217-226.

Santochi M, Dini G (1996). Use of neural networks in automated selection of technological parameters of cutting tools. Computer Integrated Manufacturing Systems 9, 137-148.

Sapuan SM, Jacob MSD, Mustapha F, Ismail N (2002). A prototype knowledge-based system for material selection of ceramic matrix composites of automotive engine components. Materials \& Design 23, 701-708.

Sardari S, Sardari D (2002). Applications of artificial neural network in AIDS research and therapy. Current Pharmaceutical Design 8, 659-670.

Sarker R, Newton C (2002). A genetic algorithm for solving economic lot size scheduling problem. Computers \& Industrial Engineering 42, 189-198.

Sasaki M, Hamada H, Kintaichi Y, Ito T (1995). Application of a neural network to the analysis of catalytic reactions Analysis of NO decomposition over Cu/ZSM-5 zeolite. Applied Catalysis A: General 132, 261-270.

Scenna NJ (2000). Some aspects of fault diagnosis in batch processes. Reliability Engineering \& System Safety 70, 95-110.

Schroeder RG (1993). 'Operations Management: decision making in the operations function.' (McGraw Hill)

Senin N, Groppetti R, Wallace DR (2000). Concurrent assembly planning with genetic algorithms. Robotics and Computer-Integrated Manufacturing 16, 65-72.

Sette S, Boullart L, Van Langenhove L (1998). Using genetic algorithms to design a control strategy of an industrial process. Control Engineering Practice 6, 523-527.

Sharma R, Singh K, Singhal D, Ghosh R (2004). Neural network applications for detecting process faults in packed towers. Chemical Engineering and Processing 43, 841-847.

Shehab EM, Abdalla HS (2001). Manufacturing cost modelling for concurrent product development. Robotics and Computer-Integrated Manufacturing 17, 341-353.

Shiva Kumar H, Krishnamoorthy CS, Rajagopalan N (1995). A process model for knowledge-based concrete bridge design. Engineering Applications of Artificial Intelligence 8, 435-447.

Shunmugam MS, Bhaskara Reddy SV, Narendran TT (2000). Selection of optimal conditions in multipass face-milling using a genetic algorithm. International Journal of Machine Tools and Manufacture 40, 401-414.

Shyur H-J, Luxhoj JT, Williams TP (1996). Using neural networks to predict component inspection requirements for aging aircraft. Computers \& Industrial Engineering 30, 257-267.

Sigman S, Liu XF (2003). A computational argumentation methodology for capturing and analyzing design rationale arising from multiple perspectives. Information and Software Technology 45, 113-122. 
Simon HA (1987). Two heads are better than one: the collaboration between AI and OR. Interfaces 17, 8-15.

Skarlatos D, Karakasis K, Trochidis A (2004). Railway wheel fault diagnosis using a fuzzy-logic method. Applied Acoustics 65, 951-966.

So SS, Karplus M (1997). Three-dimensional quantitative structure-activity relationships from molecular similarity matrices and genetic neural networks. 2. Applications. Journal Of Medicinal Chemistry 40, 4360-4371.

Soh C-K, Miles JC (1995). A framework for integrating databases with knowledge bases for structural engineering. Engineering Fracture Mechanics 50, 903-921.

Spoerre JK (1997). Application of the cascade correlation algorithm (CCA) to bearing fault classification problems. Computers in Industry 32, 295-304.

Stein EW, Manco MP, Manco SA (2001). A knowledge-based system to assist university administrators in meeting disability act requirements. Expert Systems with Applications 21, 65-74.

Stein EW, Miscikowski DK (1999). : supporting product quality with knowledge-based systems. Expert Systems with Applications 16, 365-377.

Storey VC, Dey D, Ullrich H, Sundaresan S (1998). An ontology-based expert system for database design. Data \& Knowledge Engineering 28, 31-46.

Sun J, Kalenchuk DK, Xue D, Gu P (2000). Design candidate identification using neural networkbased fuzzy reasoning. Robotics and Computer-Integrated Manufacturing 16, 383-396.

Sun Y, Peng Y, Chen Y, Shukla AJ (2003). Application of artificial neural networks in the design of controlled release drug delivery systems. Advanced Drug Delivery Reviews 55, 1201-1215.

Sung SC, Vlach M (2003). Single machine scheduling to minimize the number of late jobs under uncertainty. Fuzzy Sets and Systems 139, 421-430.

Szafnicki K, Narce C, Bourgois J (2005). Towards an integrated tool for control, supervision and operator training--application to industrial wastewater detoxication plants. Control Engineering Practice 13, 729-738.

Tan JS, Kramer MA (1997). A general framework for preventive maintenance optimization in chemical process operations. Computers \& Chemical Engineering 21, 1451-1469.

Tang J, Y.K. Fung R, Xu B, Wang D (2002). A new approach to quality function deployment planning with financial consideration. Computers \& Operations Research 29, 1447-1463.

Taniguchi E, Shimamoto H (2004). Intelligent transportation system based dynamic vehicle routing and scheduling with variable travel times. Transportation Research Part C: Emerging Technologies 12, $235-250$.

Tarifa EE, Scenna NJ (2004). Fault diagnosis for MSF dynamic states using a SDG and fuzzy logic. Desalination 166, 93-101.

Tarng YS, Yehb ZM, Niana CY (1996). Genetic synthesis of fuzzy logic controllers in turning. Fuzzy Sets and Systems 83, 301-310.

Teo CY, Gooi HB (1997). Application of knowledge-based systems for fault diagnosis and supply restoration. Engineering Applications of Artificial Intelligence 10, 631-638.

Terfloth L, Gasteiger J (2001). Neural networks and genetic algorithms in drug design. Drug Discovery Today 6, 102-108. 
Torrecilla JS, Otero L, Sanz PD (2004). A neural network approach for thermal/pressure food processing. Journal of Food Engineering 62, 89-95.

Tsai T-N (2005). Development of an integrated reflow soldering control system using incremental hybrid process knowledge. Expert Systems with Applications 28, 681-692.

Tsai Y-T, Wang K-S, Teng H-Y (2001). Optimizing preventive maintenance for mechanical components using genetic algorithms. Reliability Engineering \& System Safety 74, 89-97.

Tsuchiya T, Osada T, Kikuno T (1998). Genetics-based multiprocessor scheduling using task duplication. Microprocessors and Microsystems 22, 197-207.

Tsujimura Y, Gen M, Kubota E (1995). Solving fuzzy assembly-line balancing problem with genetic algorithms. Computers \& Industrial Engineering 29, 543-547.

Turing A (1950). Computing Machinery and Intelligence. Mind 59, 433-460.

Tyan C-Y, Wang PP, Bahler DR (1996). An application on intelligent control using neural network and fuzzy logic. Neurocomputing 12, 345-363.

Tyni T, Ylinen J (2005). Evolutionary bi-objective optimisation in the elevator car routing problem. European Journal of Operational Research In Press, Corrected Proof.

Vadera S, Meziane F, Huang M-LL (2001). Experience with mural in formalising Dust-Expert. Information and Software Technology 43, 231-240.

Vancza J, Markus A (1996). Experiments with the integration of reasoning, optimization and generalization in process planning. Advances in Engineering Software 25, 29-39.

Varde PV, Sankar S, Verma AK (1998). An operator support system for research reactor operations and fault diagnosis through a connectionist framework and PSA based knowledge based systems. Reliability Engineering \& System Safety 60, 53-69.

Varma A, Roddy N (1999). ICARUS: design and deployment of a case-based reasoning system for locomotive diagnostics. Engineering Applications of Artificial Intelligence 12, 681-690.

Villanueva H, Lamba H (1997). Operator guidance system for industrial plant supervision. Expert Systems with Applications 12, 441-454.

Vingerhoeds RA, Janssens P, Netten BD, Aznar Fernandez-Montesinos M (1995). Enhancing off-line and on-line condition monitoring and fault diagnosis. Control Engineering Practice 3, 1515-1528.

Vong CM, Leung TP, Wong PK (2002). Case-based reasoning and adaptation in hydraulic production machine design. Engineering Applications of Artificial Intelligence 15, 567-585.

Wang C, Wang D, Ip WH, Yuen DW (2002). The single machine ready time scheduling problem with fuzzy processing times. Fuzzy Sets and Systems 127, 117-129.

Wang H, Xue D (2002). An intelligent zone-based delivery scheduling approach. Computers in Industry 48, 109-125.

Wang J (2002). A fuzzy project scheduling approach to minimize schedule risk for product development. Fuzzy Sets and Systems 127, 99-116.

Wang J, Shu Y-F (2005). Fuzzy decision modeling for supply chain management. Fuzzy Sets and Systems 150, 107-127.

Wang S (2001). A hybrid threshold curve model for optimal yield management: neural networks and dynamic programming. Computers \& Industrial Engineering 40, 161-173. 
Wei XH, Wu JJ, Liang WQ (2001). Application of an artificial neural network in the design of sustained-release dosage forms. Yao Xue Xue Bao = Acta Pharmaceutica Sinica 36, 690-694.

Wen F, Chang CS (1998). A new approach to fault diagnosis in electrical distribution networks using a genetic algorithm. Artificial Intelligence in Engineering 12, 69-80.

White DJ (1975). 'Decision Methodology.' (John Wiley and Sons: London)

Wilcox LC (1996). Invited paper The role of expert systems in integrated curriculum design. Expert Systems with Applications 11, 1-11.

Xia Q, Rao M (1999). Dynamic case-based reasoning for process operation support systems. Engineering Applications of Artificial Intelligence 12, 343-361.

Xie J, Dong J (2002). Heuristic genetic algorithms for general capacitated lot-sizing problems. Computers \& Mathematics with Applications 44, 263-276.

Xue D, Yadav S, Norrie DH (1999). Knowledge base and database representation for intelligent concurrent design. Computer-Aided Design 31, 131-145.

Yang B-S, Han T, Kim Y-S (2004). Integration of ART-Kohonen neural network and case-based reasoning for intelligent fault diagnosis. Expert Systems with Applications 26, 387-395.

Yang B-S, Lim D-S, Tan ACC (2005). VIBEX: an expert system for vibration fault diagnosis of rotating machinery using decision tree and decision table. Expert Systems with Applications 28, 735742.

Yangping Z, Bingquan Z, DongXin W (2000). Application of genetic algorithms to fault diagnosis in nuclear power plants. Reliability Engineering \& System Safety 67, 153-160.

Yeow TW, Askari V, Lu Z, Kapps A, Fraser W, Goldenberg AA (2002). An expert system for generation of anti-G control schedule for jet fighter pilots. Expert Systems with Applications 22, 257266.

Yu DL, Gomm JB (2003). Implementation of neural network predictive control to a multivariable chemical reactor. Control Engineering Practice 11, 1315-1323.

Yuen CF, Wong SY, Venuvinod PK (2003). Development of a generic computer-aided process planning support system. Journal of Materials Processing Technology 139, 394-401.

Zadeh L (1962). From circuit theory to system theory. In 'Proc. IRE' pp. 856-865

Zakarian VL, Kaiser MJ (1999). An embedded hybrid neural network and expert system in a computeraided design system. Expert Systems with Applications 16, 233-243.

Zha XF, Du H (2002). A PDES/STEP-based model and system for concurrent integrated design and assembly planning. Computer-Aided Design 34, 1087-1110.

Zha XF, Lim SYE (2003). Intelligent design and planning of manual assembly workstations: A neurofuzzy approach. Computers \& Industrial Engineering 44, 611-632.

Zhang Y, Chen H (1999). A knowledge-based dynamic job-scheduling in low-volume/high-variety manufacturing. Artificial Intelligence in Engineering 13, 241-249.

Zhang Z, Friedrich K (2003). Artificial neural networks applied to polymer composites: a review. Composites Science and Technology 63, 2029-2044.

Zhao Y, Ridgway K, Al-Ahmari AMA (2002). Integration of CAD and a cutting tool selection system. Computers \& Industrial Engineering 42, 17-34. 
Zhao Z, Chen C (2001). Concrete bridge deterioration diagnosis using fuzzy inference system. Advances in Engineering Software 32, 317-325.

Zilouchian A, Jafar M (2001). Automation and process control of reverse osmosis plants using soft computing methodologies. Desalination 135, 51-59.

Zorriassatine F, Tannock JDT, O'Brien C (2003). Using novelty detection to identify abnormalities caused by mean shifts in bivariate processes. Computers \& Industrial Engineering 44, 385-408. 